\title{
Landscape of gene fusions in epithelial cancers: seq and ye shall find
}

\author{
Chandan Kumar-Sinha ${ }^{1,2^{*}}$, Shanker Kalyana-Sundaram ${ }^{1,2}$ and Arul M. Chinnaiyan 1,2,3,4,5,6*
}

\begin{abstract}
Enabled by high-throughput sequencing approaches, epithelial cancers across a range of tissue types are seen to harbor gene fusions as integral to their landscape of somatic aberrations. Although many gene fusions are found at high frequency in several rare solid cancers, apart from fusions involving the ETS family of transcription factors which have been seen in approximately $50 \%$ of prostate cancers, several other common solid cancers have been shown to harbor recurrent gene fusions at low frequencies. On the other hand, many gene fusions involving oncogenes, such as those encoding ALK, RAF or FGFR kinase families, have been detected across multiple different epithelial carcinomas. Tumor-specific gene fusions can serve as diagnostic biomarkers or help define molecular subtypes of tumors; for example, gene fusions involving oncogenes such as ERG, ETV1, TFE3, NUT, POU5F1, NFIB, $P L A G 1$, and PAX8 are diagnostically useful. Tumors with fusions involving therapeutically targetable genes such as ALK, RET, BRAF, RAF1, FGFR1-4, and NOTCH1-3 have immediate implications for precision medicine across tissue types. Thus, ongoing cancer genomic and transcriptomic analyses for clinical sequencing need to delineate the landscape of gene fusions. Prioritization of potential oncogenic "drivers" from "passenger" fusions, and functional characterization of potentially actionable gene fusions across diverse tissue types, will help translate these findings into clinical applications. Here, we review recent advances in gene fusion discovery and the prospects for medicine.
\end{abstract}

\section{Introduction}

Recurrent chromosomal rearrangements in cancers have been described for over half a century $[1,2]$. The characterization of the oncogenic fusion $B C R-A B L 1$ at $\mathrm{t}(9,22)$ translocation loci in chronic myeloid leukemia, which culminated in the development of a molecularly targeted therapy, provides a compelling "bench to bedside" paradigm for cancers [3, 4]. Numerous gene fusions have since been defined at cytogenetically distinct loci of recurrent chromosomal aberrations in hematological malignancies and sarcomas, as well as in solid cancers, albeit much less frequently, arguably owing to technical limitations in resolving karyotypically complex, heterogeneous sub-clones in solid tumor tissues $[5,6]$. The serendipitous discovery of ETS family gene fusions in common prostate carcinoma $[7,8]$, and of ALK and ROS kinase fusions in lung cancer $[9,10]$ through transcriptomic and proteomic approaches, bypassing chromosomal analyses, provided a strong fillip

\footnotetext{
* Correspondence: chakumar@umich.edu; arul@umich.edu

${ }^{1}$ Michigan Center for Translational Pathology, University of Michigan Medical School, Ann Arbor, Ml 48109, USA

Full list of author information is available at the end of the article
}

to the search for gene fusions in common solid cancers and pointed to alternative approaches to gene fusion discovery. Developments in high-throughput sequencing techniques over the past decade [11] have made possible a direct, systematic discovery of gene fusions in solid cancers [12-14], rapidly revealing a diverse genomic landscape. Gene fusions have now been identified in several common carcinomas, including those of the prostate, lung, breast, head and neck, brain, skin, gastrointestinal tract, and kidney, which alongside the widely documented gene fusions in thyroid and salivary gland tumors support the notion that gene fusions are integral to the genomic landscape of most cancers.

Here, we review the emerging landscape of gene fusions across solid cancers, focusing on the recent spurt of discoveries made through sequencing. We review common features of "driver" fusions (those that contribute to tumor progression), the major functional classes of fusions that have been described, and their clinical, diagnostic and/or therapeutic implications.
C Biomed Central

(c) 2015 Kumar-Sinha et al. Open Access This article is distributed under the terms of the Creative Commons Attribution 4.0 International License (http://creativecommons.org/licenses/by/4.0/), which permits unrestricted use, distribution, and reproduction in any medium, provided you give appropriate credit to the original author(s) and the source, provide a link to the Creative Commons license, and indicate if changes were made. The Creative Commons Public Domain Dedication waiver (http://creativecommons.org/publicdomain/zero/1.0/) applies to the data made available in this article, unless otherwise stated. 


\section{Detection of gene fusions in carcinoma}

The first gene fusions to be defined in solid cancers, RET/PTC [15] and NTRK1 [16] rearrangements in papillary thyroid carcinoma were identified through a "transformation assay" using cancer genomic DNA transfected into murine NIH3T3 cells, followed by retrieval and analysis of human genomic DNA from transformed cells [17]. More typically, karyotyping and cytogenetic analysis of recurrent translocations helped define early gene fusions in solid cancers, such as CTNNB1-PLAG1 [18] and $H M G A 2$ fusions [19] in salivary gland pleomorphic adenomas, PRCC-TFE3 in renal cell carcinomas [20], and ETV6-NTRK3 fusion in secretory breast carcinoma [21]. Incorporating more molecular approaches, a recurrent $2 q 13$ breakpoint locus, $\mathrm{t}(2 ; 3)(\mathrm{q} 13 ; \mathrm{p} 25)$, in follicular thyroid carcinoma was fine mapped using yeast artificial chromosomes, and cloned through 3' rapid amplification of cDNA ends (RACE) of the candidate $P A X 8$ cDNA, leading to characterization of the $P A X 8-P P A R \gamma$ gene fusion [22]. Anticipating high-throughput genomics approaches, an expressed sequence tag (EST) mapping to the recurrent chromosomal breakpoint at $\mathrm{t}(15 ; 19)(\mathrm{q} 13 ; 13.1)$ in midline carcinoma was identified from an EST database and cloned through RACE to identify the pathognomonic gene fusion BRD4-NUT [23]. The gene fusions defined in solid cancers thus far were localized at cytogenetically distinct, recurrent chromosomal aberrations, and were largely confined to relatively rare subtypes of solid cancers [5].

However, between 2005 and 2007, independent of a priori evidence of genomic rearrangements, recurrent gene fusions involving ETS family genes were discovered in prostate cancer, based on analysis of genes displaying outlier expression [7, 8, 24]. Around the same time, a transformation assay with a cDNA expression library (not genomic libraries [17]) from a lung adenocarcinoma sample led to the discovery of $E M L 4-A L K$ fusions [10], and a high-throughput phosphotyrosine signaling screen of lung cancer cell lines and tumors identified SLC34A2ROS1 fusions in non-small-cell lung carcinoma (NSCLC) [9]. Thus, analyses of cancer RNA and proteins provided a critical breakthrough in the identification of oncogenic gene fusions in common carcinoma. In Fig. 1, we summarize the timeline of gene fusion discoveries, 100 years since Boveri's prescient hypothesis that malignant tumor growth is a consequence of chromosomal abnormalities, including "combinations of chromosomes" [25].

\section{Next-generation sequencing}

High-throughput sequencing of tumor samples provides a direct readout of chimeric sequences corresponding to putative gene fusions, and the available depth of coverage helps uncover even relatively minor, sub-clonal events. In a proof of principle study, high-throughput genomic sequencing was used to identify several gene fusions in a panel of breast cancer cell lines and tissues [14]. However, considering that only a small subset of genomic breakpoints correspond to gene fusions encoding fusion transcripts or proteins, alternative approaches were explored. In a directed approach, focusing on chimeric transcripts as the readout of "expressed" gene fusions, Maher and colleagues used coupled short- and long-read transcriptome sequencing [12] and paired-end transcriptome sequencing [13] to detect chimeric RNAs that could be analyzed to characterize gene fusions. RNA sequencing has since been widely used in the discovery of numerous gene fusions in diverse epithelial cancers. Additionally, paired-end tag [26] and chromatin interaction analysis by paired-end-tag sequencing have been employed for gene fusion discovery [27], as well as phosphoproteome analysis, as in the discovery of a SND1-BRAF fusion in a gastric carcinoma sample [28].

\section{Box 1. Summary points}

1. Gene fusions are an integral component of the landscape of somatic aberrations in all cancers.

2. Recurrent 5' fusion genes are generally lineage- and/or cell-type specific.

3. Recurrent $3^{\prime}$ fusion genes in epithelial cancers are usually kinases or transcription factors, similar to the situation in hematological and soft tissue cancers.

4. High-throughput sequencing enables systematic discovery of gene fusions with high sensitivity and precision.

5. High-throughput sequencing often identifies multiple gene fusions in individual samples, presenting a challenge to distinguish oncogenic "driver" from unimportant "passenger" aberrations.

6. Chimeric RNAs expressed independent of chromosomal rearrangements are frequently observed in cancer (and benign) tissues.

7. Functionally recurrent gene fusions provide clinically relevant molecular subclassifications of existing morphological categories of tumors.

8. Functionally recurrent gene fusions that are seen across tissue types define functionally distinct molecular subtypes of cancers.

9. Gene fusions represent personalized therapeutic targets and prognostic and diagnostic markers. 


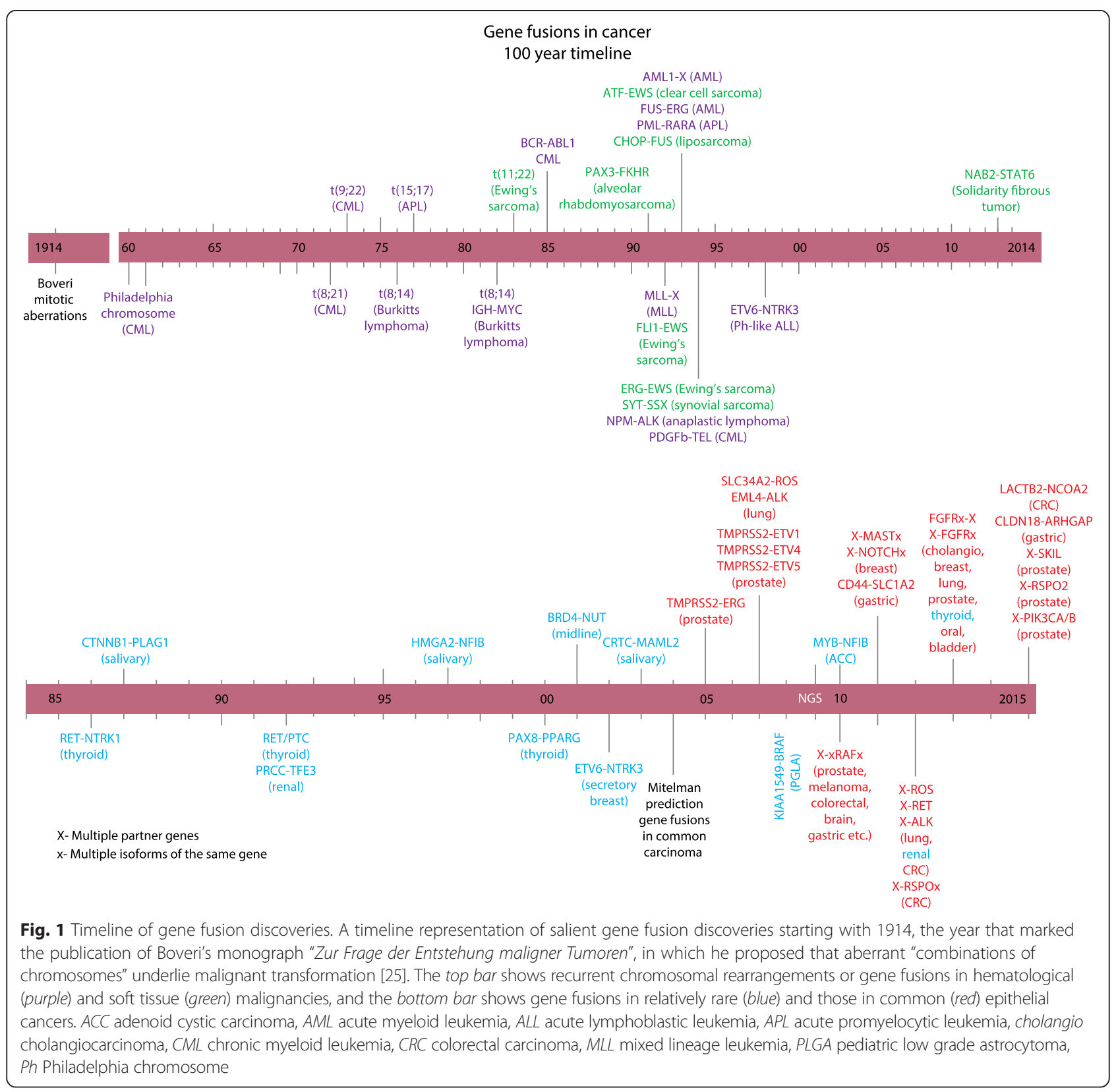

The DNA- or protein-based methods, however, are not as commonly used as RNA sequencing, likely owing to several additional, specialized steps that are involved.

Interestingly, RNA sequencing has also identified a class of chimeric RNAs that do not involve chromosomal aberrations. For example, "read-through" chimeric SLC45A3-ELK4 transcripts, such as those detected in prostate cancer, result from runaway transcription of the androgen-inducible, prostate-specific gene SLC45A3 into $E L K 4$, the adjacent ETS family gene in the same orientation [12, 29-31]. Similarly, the VTI1A-TCF7L2 fusion, originally identified through genomic sequencing of colorectal carcinoma (CRC) samples [32], was found in a follow-up study using RNA analyses to be quite prevalent in other cancers, as well as in benign samples [33]. Chimeric transcripts not associated with genomic translocation have also been observed between non-contiguous genes. Guerra and colleagues identified CCND1TACSTD2 (TROP2) chimeric mRNA that involves genes located on different chromosomes in subsets of ovarian, breast, gastrointestinal, and endometrial cancers [34]. The functional significance of these RNA chimeras is not clear at present, as their expression is typically seen to be relatively non-specific. 


\section{Driver and passenger gene fusions}

High-throughput sequencing of cancer samples frequently identifies multiple gene fusions in individual samples, often presenting a challenge for identifying potentially oncogenic driver fusions among irrelevant passenger aberrations. Some useful generalizations have emerged from multiple analyses: first, driver fusions are typically marked by a continuous open reading frame (ORF) that retains functional domains, such as the kinase domain in gene fusions involving oncogenic kinases, or DNA-binding domains in the case of transcription factors; second, some fusions display loss of auto-inhibitory domains (for example, loss of the $\mathrm{N}$-terminal inhibitory domain in the product of BRAF fusions, or loss of 3' UTR sequences in FGFR or HMGA2 fusions that serve as binding sites for inhibitory microRNAs). Yet other types of fusions juxtapose the promoter of certain tissue-specific, inducible or highly expressed genes; for example, the prostate-specific, androgen-inducible genes TMPRSS 2 or $S L C 45 A 3$ fused in frame with the proto-oncogenes $E R G$ or $B R A F$, respectively, generate the TMPRSS2-ERG and SLC45A3-BRAF gene fusions in prostate cancer.

In the case of novel gene fusions involving less characterized genes, distinguishing candidate driver fusions from random events is complicated by the many false positive candidates resulting from alignment artifacts, such as multi-mapping of reads owing to homologous (pseudogenes) and/or repetitive sequences, and sequencing artifacts due to errors in library generation (particularly ligation and PCR artifacts) and sequencing. Incorporating these considerations, and additional bioinformatics filters, various bioinformatics pipelines have been developed to help prioritize fusion candidates from next-generation sequencing (NGS) data, including Chimerascan [35], FusionSeq [36], DeFuse [37], TopHat-Fusion [38], PRADA [39], and JAFFA [40]. While useful to help reduce the number of false candidates, the output from bioinformatics pipelines needs to be further validated, preferably followed by functional assays, before designating candidate gene fusions as novel driver aberrations. Recurrence of fusions, fusion partners or partner gene families in gene fusion databases also helps to prioritize candidate fusions. Once validated, screening for novel gene fusions in larger cohorts of samples employs quantitative RT-PCR or more recent techniques such as nano-string-based detection [41-43].

\section{Overview of the landscape of gene fusions in epithelial cancers}

From the first reported chromosomal rearrangements in the 1960s up to the year 2000 (roughly marking the advent of high-throughput molecular techniques), the Mitelman Database of Chromosome Aberrations and Gene Fusions in Cancer catalogued more than 600 "recurrent balanced neoplasia-associated aberrations", in which solid cancers accounted for less than $20 \%$ [44]; in its latest update (7 May 2015), this database lists 10,004 "gene fusions" [45], with solid cancers accounting for a much greater proportion, and with a large number of these fusions identified by recent high-throughput gene expression or sequencing analyses. Over the last decade, numerous gene fusions have been characterized in diverse solid cancers, including ETS family gene fusions in prostate cancer $[7,8,12,30,46-56]$; ALK, ROS1 and RET kinase fusions in lung cancer [9, 10, 57-69]; RAF kinase fusions in brain tumors [70-80], melanoma [81, 82], gastric cancer [28, 82], and prostate cancer [82, 83]; $\mathrm{R}$-spondin fusions in colorectal and prostate cancer [83, 84]; CD44-SLC1A2 gene fusions in gastric cancer [85]; MAST- and NOTCH-family gene fusions in breast cancer [86]; MITF gene fusions in renal cancer [87]; and a number of FGFR family fusions in diverse cancer types [88] (Table 1). More than 8000 gene fusions across 16 different tumor types are tabulated in The Cancer Genome Atlas (TCGA) Fusion gene Data Portal (http://www. tumorfusions.org) [89]. The key points regarding gene fusions in epithelial cancers are summarized in Box 1.

These gene fusions in solid cancers encompass the diversity of fusion architectures, as shown in Fig. 2 and Box 2, and represent a spectrum of functional categories, including those described earlier such as kinases and transcription factors, as well as those involving newer pathways and loss-of-function fusions (discussed later). Notably, even as numerous novel gene fusions are being discovered fairly rapidly, most of these are either non-recurrent singletons, or are seen to recur at exceedingly low frequency in tumor subtypes or to recur across tumor types (Table 1). Incidentally, gene fusions displaying molecular recurrence involving both $5^{\prime}$ and $3^{\prime}$ partner genes, as in TMPRSS2ERG, EML4-ALK, and BRD4-NUT, are relatively few. A large number of fusions display recurrence of a fusion gene in combination with multiple different partners; for example, BRAF/RAF1 [76, 79, 82, 83] and FGFR1/2/3 [8894] are fused to several different 5 ' partners across different tissue types (Additional file 1). This heterogeneity is likely reflective of the diverse tissue-physiological milieu in which these oncogenes impart selective advantage to the cancer cells. Conversely, some lineage-specific genes are seen to serve as $5^{\prime}$ partners across multiple different $3^{\prime}$ genes; for example, TMPRSS2 and SLC45A3 in prostate cancer have been observed as $5^{\prime}$ partners of ERG, ETV1, ETV4, ETV5, BRAF, and ELK4 (Table 1 and Additional file $1)$. Another type of observed "recurrence" involves isoforms of a gene family - for example, ETV1/2/3/4/5, FGFR1/2/3, BRAF/RAF1, BRD3/4, CRTC1/CRTC3, and $N T R K 1 / 3$ - as fusion partners. Considering that individual fusions may be observed relatively rarely (even uniquely), the potential functional consequences of gene fusions assumes priority over considerations of recurrence. 


\section{Box 2. Mechanisms of generation of gene fusions}

An overview of the genomic architecture of gene fusions reveals that fusions may result from insertion, deletion, inversion, or tandem duplication or amplification, and may involve the same chromosome (intra-chromosomal) or different chromosomes (inter-chromosomal) (Fig. 2). A majority of chromosomal rearrangements have been associated with intra-chromosomal tandem duplications and amplifications in multiple whole-genome sequencing studies [14, 26, 80, 150]. Micro-homologies and repeat elements have been associated with loci of recurrent break points [151]. In an analysis of RAF family gene fusion breakpoints in low-grade astrocytomas, tandem duplications generated by microhomology-mediated break-induced replication were identified as the mechanism of generation of fusions [74].

Spatial proximity between distant chromosomal loci has been associated with chromosomal rearrangements, as observed between RET and the $\mathrm{H} 4$ genes located 30 megabases (Mb) apart on chromosome 10, involved in RET gene fusions in papillary thyroid carcinoma [152]. This proximity may be induced by genotoxic stress; for example, androgen stimulation coupled with the genotoxic stress of radiation was shown to generate gene fusions through "induced proximity" between TMPRSS2 and ERG (located on chromosome 21q22.2, approximately $3 \mathrm{Mb}$ apart) as well as between TPMRSS2 and ETV1 (located on chromosome 7) [153, 154] (Fig. 3a). Another phenomenon, called chromothripsis, describes the frequent occurrence of massive chromosomal aberrations localized to only one or two chromosomes, with fragments of chromosome joined randomly $[155,156]$. Chromothripsis may be responsible for the generation of numerous, apparently random passenger gene fusions that are retained in the multiclonal cells of epithelial cancers, as well as loss-offunction fusions involving tumor suppressors, likely involving the non-homologous end-joining DNA repair system (Fig. 3b).

Several cancer-causing viruses, such as Epstein-Barr virus (EBV), Kaposi's sarcoma-associated herpesvirus (KSHV), human papilloma virus (HPV), hepatitis B and C viruses (HBV and HCV), and Merkel cell polyomavirus (MCV), integrate into human genomic DNA at defined hotspots as well as seemingly randomly [157]. Viral integration events have been associated with chromosomal aberrations, such as MYC amplification in HPVpositive genital carcinoma [158], and not uncommonly, loss of gene function [159, 160] or gene fusions involving viral-human sequences have been reported [161, 162]. The recent report of a recurrent gene fusion of UBR5 on 8q22.3 and ZNF423 on 16q12.1 (UBR5-ZNF423) in $8 \%$ of EBVassociated primary nasopharyngeal carcinomas suggests a driver function of this gene fusion in a subset of nasopharyngeal cancers [163].

\section{Functional consequences of gene fusions}

Functionally distinct molecular classes of gene fusions that are shared across tumor types can be identified in solid cancers.

\section{Kinases}

Given their therapeutic importance, identification of gene fusions involving kinases can often signify a clinically actionable observation. Kinase fusion genes detected across multiple cancer types include RET, NTRK1, NTRK3, ALK, ROS1, FGFR1/2/3, and serine threonine kinases including the RAF family genes $B R A F, R A F 1$, $C R A F$, and MAST1/2 (Table 1 and Additional file 1). In most gene fusions involving kinases, the kinase domain is retained [95], and this provides a strong filtering criterion in high-throughput sequencing data analysis. Analysis of mRNA sequencing data from the TCGA compendium, comprising 4366 primary tumor samples from 13 tissue types, revealed kinase fusions involving ALK, ROS, RET, NTRK, and FGFR gene families, which were detected in several types of cancer: bladder carcinoma (3.3\%), glioblastoma (4.4\%), head and neck cancer (1.0\%), low-grade glioma (1.5\%), lung adenocarcinoma (1.6\%), lung squamous cell carcinoma (2.3\%), and thyroid carcinoma (8.7\%) [89].

\section{Transcription factors}

Gene fusions involving dysregulated expression of transcription factors include ETS family gene fusions, seen in approximately $50 \%$ of all prostate cancers and probably one of the most prevalent transcription factor gene fusions in common epithelial cancers. Among these, $E R G$ represents the most common fusion partner and ETV1 the most promiscuous, with a dozen or more different fusion partners described to date (Additional file 1) $[24,96]$.

Other gene fusions involving transcription factors include NUT (or NUTM1), POU5F1, MAML2, NFIB, PLAG1, TFE3, NOTCH, and PAX8 fusions, imparting spatially and/or stochastically dysregulated expression in multiple different cancer types. NOTCH1 and $\mathrm{NOTCH} 2$ fusions result in dysregulated transcriptional outcomes, because after ligand activation, the NOTCH intracellular domain (NICD) forms a transcriptional activator complex, activating genes involved in differentiation, proliferation and apoptosis, and those associated with carcinogenesis. MAML2 acts as a transcriptional coactivator for $\mathrm{NOTCH}$ proteins by amplifying $\mathrm{NOTCH}-$ induced transcription of HES1. TFE3, which belongs to the MITF/TFE family of basic helix-loop-helix leucine zipper transcription factors, is involved in TGF- $\beta$ induced transcription, and has important roles in cell 
Table 1 Recurrent gene fusions in epithelial cancers of different body tissues and their role as clinical biomarkers

\begin{tabular}{|c|c|c|c|c|c|}
\hline $\begin{array}{l}\text { Tissue or body } \\
\text { region }\end{array}$ & Tumor type & Aberration & Genetic alteration & Diagnostic/prognostic/therapeutic significance & Reference \\
\hline \multirow[t]{3}{*}{ Thyroid gland } & \multirow[t]{3}{*}{$\begin{array}{l}\text { Papillary thyroid cancer (PTC) } \\
\text { ( }>80 \% \text { of thyroid cancers) }\end{array}$} & RET gene fusions & $\begin{array}{l}\text { Multiple different 5' partners (most common } \\
\text { being CCDC6 (PTC1) and NCOA4 (PTC3)) fuse to } 3^{\prime} \\
\text { partner RET }\end{array}$ & $\begin{array}{l}10-30 \% \text { of PTC cases. RET is an oncogenic } \\
\text { receptor tyrosine kinase sensitive to FDA- } \\
\text { approved drugs, including vandetanib and } \\
\text { cabozantinib }\end{array}$ & [15] \\
\hline & & NTRK1 gene fusions & $\begin{array}{l}5^{\prime} \text { activating gene partners including TPM3, TPR } \\
\text { and TGF fuse with } 3^{\prime} \text { partner NTRK1 }\end{array}$ & $\begin{array}{l}5 \% \text { of PTC cases. NTRK1 is an oncogenic receptor } \\
\text { tyrosine kinase, potentially targetable by kinase } \\
\text { inhibitors }\end{array}$ & {$[15,16]$} \\
\hline & & ETV6-NTRK3 & $\begin{array}{l}\text { Chromosomal translocation t(12;15) (p13;q25) } \\
\text { generates the fusion, with the dimerization } \\
\text { domain of ETS family transcription factor (TF) ETV6 } \\
\text { fused to the tyrosine kinase domain of NTRK3. } \\
\text { Involves exon } 14 \text { of NTRK3, unlike other ETV6- } \\
\text { NTRK3 fusions, which involve exon } 13\end{array}$ & $\begin{array}{l}\text { Radiation-associated PTC ( } 14.5 \% \text { post-Chernobyl); } \\
2 \% \text { of sporadic PTC cases. Second only to RET } \\
\text { fusions in prevalence }\end{array}$ & [121] \\
\hline
\end{tabular}

Radiation-induced PTC AKAP9-BRAF

Follicular thyroid carcinoma (FTC) (10-20\% of thyroid cancers)

Head and neck Pleomorphic adenoma

PAX8-PPARY
In-frame fusion between exons 1-8 of the AKAP9 gene and exons 9-18 of BRAF protein kinase gene, lacking the auto-inhibitory $\mathrm{N}$-terminal domain

Chromosomal translocation t(2;3)(q13;p25) results in chimeric protein involving the DNA-binding domain of the thyroid-specific TF PAX8 fused to PPARY

PLAG1 gene fusions Multiple 5' partners (CHCHD7, CTNNB1, FGFR1, LIFR,

HMGA2 gene

fusions

HMGA2 is fused with different $3^{\prime}$ partners (including FHIT, NFIB, and WIFI)

FGFR-PLAGI

Adenoid cystic carcinomas (salivary glands, lacrimal glands, ceruminal glands; also breast)

Acinic cell carcinoma

cystadenocarcinoma, mammary

analogue secretory carcinoma of

salivary glands (MASC)

FGFR is the 5' partner, which, without its kinase domain, provides the promoter to drive the expression of the $3^{\prime}$ partner, PLAGI

Inter-chromosomal gene fusion generating a chimeric transcript comprising almost the entire reading frame of the MYB oncogene fused to the last two exons of NFIB

ETV6-NTRK3 (TEL- Chromosomal translocation t(12;15) (p13;q25) generates the ETV6-NTRK3 fusion, with the dimerization domain of the ETS family TF ETV6 fused to the tyrosine kinase domain of NTRK3 TCEA1) fuse to $3^{\prime}$ PLAG

Fusion-positive tumors lack BRAF-activating point mutations. Fusion causes constitutive activation of BRAF and downstream MAPK pathways. Thus, a potential target for MEK inhibitors

Fusion-positive FTCs appear to have a significantly better prognosis compared with those lacking this fusion. FTC cells expressing PAX8-PPARY fusion protein show reduced tumor progression in mouse xenograft model

PLAG1 encodes a zinc finger TF that regulates IGF2 mitogenic signaling pathway

The fusion retains all the functional domains of HMGA2, and removes the $3^{\prime}$ UTR sequence that contains several inhibitory let7 microRNA binding sites. Absence of the Let-7-regulated 3' UTR in the fusion transcript results in overexpression of HMGA2 that is sufficient for neoplastic transformation
This FGFR fusion product does not include the FGFR kinase domain, and therefore is not a target for FGFR inhibitors

MYB likely provides the oncogenic activity, while NFIB primarily replaces a potentially inhibitory $3^{\prime}$ UTR of MYB

This fusion is now considered pathognomonic of MASC 
Table 1 Recurrent gene fusions in epithelial cancers of different body tissues and their role as clinical biomarkers (Continued)

Mucoepidermoid carcinoma (MEC) in CRTC1-MAML1 or the oral cavity (also lung, cervix and CRTC3-MAML2 thyroid glands, and clear cell

hidradenoma of skin)

Midline anatomical Nut midline carcinoma (NMC)

BRD-NUT

structures

Generated by chromosomal translocation

Translocations at the Xp11.2 breakpoint result in 5 ' partners (ASPSCRI, PRCC, NONO, CLTC, and SFPO)

ALK fusions

Non-clear cell renal cell carcinoma

CLTC-TFEB (ncCRCC)

ACTG1-MITF

Fusions involving other ETS family genes, including ETV1, ETV4, ETV5, ELK4, and FLI1

RAF gene fusions (SLC45A3-BRAF and ESRP1-RAF1)

TMPRSS2-SKIL, SLC45A3-SKIL, MIPEP SKIL, PIPOL 1-SKIL, t(11:19)(q14-21:p12-13). The product of the 3 partner MAML2 acts as a co-activator of the $3{ }^{\prime \prime}$ partner MAML2 acts as a co-activator of NOTCH oncogenic phenotype.

$75 \%$ of NMCs express BRD4-NUT fusion proteins, the rest harbor $B R D 3$ or other $5^{\prime}$ partner genes fused to NUT. BRD-NUT fusion proteins contain the N-terminal BET bromodomain, extraterminal domain, and nuclear localization signal fused to the entire coding region of NUT protein that con tains a histone acetyltransferase binding domain gene fusions involving the TFE3 gene with various

In VCL-ALK fusions, the $3^{\prime}$ portion of the ALK transcript encoding the kinase domain is fused frame to the $5^{\prime}$ portion of $\mathrm{VCL}$

This encodes an in-frame fusion protein containin the conserved bHLH domain of TFEB (similar to the "MITF high" phenotype

In this fusion protein the first 118 amino acids of MITF are replaced by the N-terminal 121 amino acids of ACTG

The 5' partner TMPRSS2 contributes prostatespecific, androgen-inducible upstream regulatory elements fused to the $3^{\prime}$ partner, encoding oncogenic ETS family TF ERG

The CRTC-MAML2 fusion is restricted to MEC and has been associated with favorable prognosis.

$[107,108$,

$110-114$

$116,117]$

NMC is a rare but aggressive squamous cell carcinoma originating from midline anatomical structures such as the head, neck or mediastinum (including the bladder, thymus, lung, and skeleton) that is defined by the presence of $B R D$ NUT fusions. BRD proteins have recently emerged as promising therapeutic targets

$15 \%$ of patients with RCC aged $<45$ years have this aberration. Fusion-positive RCCs in older

patients are more aggressive

Found in pediatric RMC that affects young black individuals with the sickle cell trait. In two independent reports, RMC tumors from three cases of African-American children with sickle cell anemia were found to harbor the VCL-ALK fusion

Associated with high expression of the antiapoptotic protein BIRC7, thus potentially sensitive to apoptosis-sensitizing BIRC7 inhibitors that are under development

Although found in only one sample, ectopic expression of the ACTG1-MITF fusion led to cellular transformation, suggesting a potential driver

function

Probably the most prevalent gene fusion in epithelial carcinoma, with $40-50 \%$ of localized prostate cancers found to harbor this fusion across multiple independent cohorts around the world. Associated with prostate carcinogenesis and distinct clinical correlates compared with fusion-negative prostate cancers

$5^{\prime}$ partners include androgen-inducible genes such Together these represent 10-20\% of localized as TMPRSS2, SLC45A3, and FLI35294, and prostate cancers

androgen-repressed C15ORF21, or housekeeping

genes such as HNRPA2B1 and DDX5, fused to

multiple 3' oncogenic ETS family TF genes

SLC45A3 is a prostate-specific, androgen-inducible Although rare, BRAF/RAF1 fusions represent

gene fused upstream to gene encoding

Although rare, BRA
therapeutic targets activation of this potent oncogene

5' partners TMPRSS2, SLC45A3, and ACPP contribute SKIL fusions are observed in 1-2\% of prostate SKIL fusions are observed in $1-2 \%$ of prostate
cancers and potentially upregulate the TGF- $\beta$ pathway 
Table 1 Recurrent gene fusions in epithelial cancers of different body tissues and their role as clinical biomarkers (Continued)

ACPP-SKIL,

HMGN2P46-SKIL

TBXLRT-PIK3CA

$A C P P-P I K 3 C B$

GRHL2-RSPO2

ALK gene fusions (most commonly

EML4-ALK, but also TFG-ALK)

ROS1 gene fusions

ET gene fusions

ETV6-NTRK3 (TEL-

TRKO

Mammary gland Breast cancer

EML4-ALK

RAF gene fusions

MAST1 and MAST2 gene fusions

NOTCH gene fusions regulatory elements fused to $3^{\prime}$ partner SKIL, a

negative regulator of SMAD

Index cases with PIK3CA/B fusions show outlier expression of PIK3CA/B. ACPP imparts androgen-

PIK3CA fusions may be responsive to PIK3CA

inhibitors

responsive expression to PIK3CB

sdex cases with RSPO2 fusions/rearrangements show outlier expression of RSPO2

RSPO2 is an agonist of the Wnt pathway and

therefore may be responsive to porcupine

inhibitors

EML4-ALK fusion encodes the N-terminal portion of EML4 fused to the intracellular portion of ALK always retaining the tyrosine kinase domain

EML4-ALK fusion is reported in 3-7 \% of patients with NSCLC in different cohorts. ALK-fusionpositive lung cancers are sensitive to the FDA-

approved kinase inhibitor crizotinib

$2 \%$ of lung cancer samples in one study

Multiple 5 " partners such as TPM3, SDC4, SLC CD74, EZR, LRIG3, and GOPC fused to ROS1. All of the fusion proteins retain the kinase domain of ROS1

Lung cancer cases with RET fusions may be candidates for FDA-approved RET inhibitor therapies such as vandetan

Almost $100 \%$ of secretory breast carcinomas. ETV6-NTRK3 chimeric protein activates the IRS1 adapter protein, RAS-MAP kinase and PI3K-AKT pathways, and suppresses TGF- $\beta$ signaling. ETV 6 pathways, and suppresses TGF- $\beta$ signaling. ETV6NTRK3-expressing cells and tumors are sensitive to the IGIFR/INSR kinase inhibitors BMS-536924 and BMS-754807 (currently in clinical trials)

5' partners including ZNF700, NFIX, and TADA2A fused to MAST1. ARIDIA and GPBPIL1 fused to MAST2 serine/threonine kinase. All MAST fusions encode contiguous open reading frames, some retaining the canonical serine/threonine kinase domain, all retaining the PDZ domain and a $3^{\prime}$ kinase-like domain SEC16A-NOTCH1, SEC22B-NOTCH2, NOTCH1 exon 2-exon 28 (intramolecular rearrangement)

$\mathrm{NOTCH}$ fusions retain the $\mathrm{NOTCH}$ intracellular domain, which mediates downstream NOTCH signaling. The SEC16A-NOTCH1 fusion retains the $Y$-secretase cleavage site and shows sensitivity to $\gamma$-secretase inhibitors compared with SEC22B-

$\mathrm{NOTCH} 2$, which loses this site

EML4 exon 13 fused to ALK exon 20, similar to NSCLC fusions

One exon array profiling study reported EML4-ALK fusions in $2.4 \%$ of breast carcinomas (5 of 209).

One EML4-ALK fusion was detected in

inflammatory breast cancer

AGTRAP-BRAF: N-terminal protein AGTRAP fused to the C-terminal kinase domain of BRAF. SND1-BRAF:
Both these fusions retain the kinase domain of BRAF, indicating potential responsiveness to RAF/ MEK inhibitors 
Table 1 Recurrent gene fusions in epithelial cancers of different body tissues and their role as clinical biomarkers (Continued)

5' SND1 gene fused to BRAF, found in GTL16 gastric

cancer cell line

CLDN18-ARHGAP26 CLDN18 on 3q22.3 fused to ARHGAP26 on 5q31.3. $3 \%$ of Southeast Asian gastric cancers

The fusion protein loses the $\mathrm{PH}$ domain of

ARHGAP26, but retains the Rho-GAP and SH3

domains

CD44-SLC1A2 Fusion involving adjacent genes (lying in opposite $1-2 \%$ of gastric cancers orientations on chromosome 13p)

the functional

Recurrent fusions involving R-spondin family domain of the R-spondins, which are known to be genes, EIF3E-RSPO2 (two cases) and PTPRK-RSPO3 agonists of the canonical Wnt/ $\beta$-catenin signaling pathway

(five cases) were detected by RNA sequencing of

LACTB2-NCOA2

The fusion disrupts expression of NCOA2, which is

68 "microsatellite stable" subtype CRC samples an inhibitor of the $W n t / \beta$-catenin pathway. This

loss-of-function fusion thus represents a novel

oncogenic mechanism in a subset of CRC

VTI1A-TCF7L2, RP11- Gene fusion involving activator of Wnt/B-catenin 57H14.3- TCF7L2 signaling pathway. VTI1A-TCF7L2 fusion lacks the TCF4 $\beta$-catenin-binding domain

VTI1A-TCF7L2 was found in 3 of 97 CRCs. A screen for TCF7L2 fusion transcripts revealed its presence in more than $80 \%$ of CRCs, $29 \%$ of normal colonic mucosa, and $25-75 \%$ of normal tissues from other organs. Thus, TCF7L2 fusion transcripts are neither specific to cancer nor to the colon or rectum. TCF7L2 fusion transcripts represent "read through" events

Skin Melanoma

Central nervous

system

Gliomas

Pilocytic astrocytoma
BRAF and RAF

gene fusions

Other, non-

recurrent

aberrations

PTPRZ1-MET

BRAF/RAF1 gene fusions
Diverse $\mathrm{N}$-terminal proteins fused to the BRAF/RAF Seen in $3 \%$ of melanomas: fusions retain the kinase domain kinase domain of BRAF, indicating potentia responsiveness to RAF/MEK inhibitors

RB1-ITM2B, PARP1-MIXL1, RECK-ALX3, TMEM8B-TLN1, CCT3-C1Orf61, GNA12-SHANK2, ANKHD1-C5Orf32

11 novel gene fusions were identified in patient samples, including both inter- and intra-chromosomal events. These fusions encode putative dominant-negative proteins (RB1, PARP1), and a truncated inhibitor of tumor invasion and metastasis (RECK)

The fusion involves translocation of introns 3 or 8 Found only in grade III astrocytomas (1/13; $7.7 \%)$ of PTPRZ and intron 1 of MET or secondary GBMs $(3 / 20 ; 15.0 \%)$

Most frequently observed in pediatric brain tumors. Approximately $80 \%$ of pilocytic astrocytomas and other low-grade gliomas harbor the KIAA1549-BRAF gene fusion 


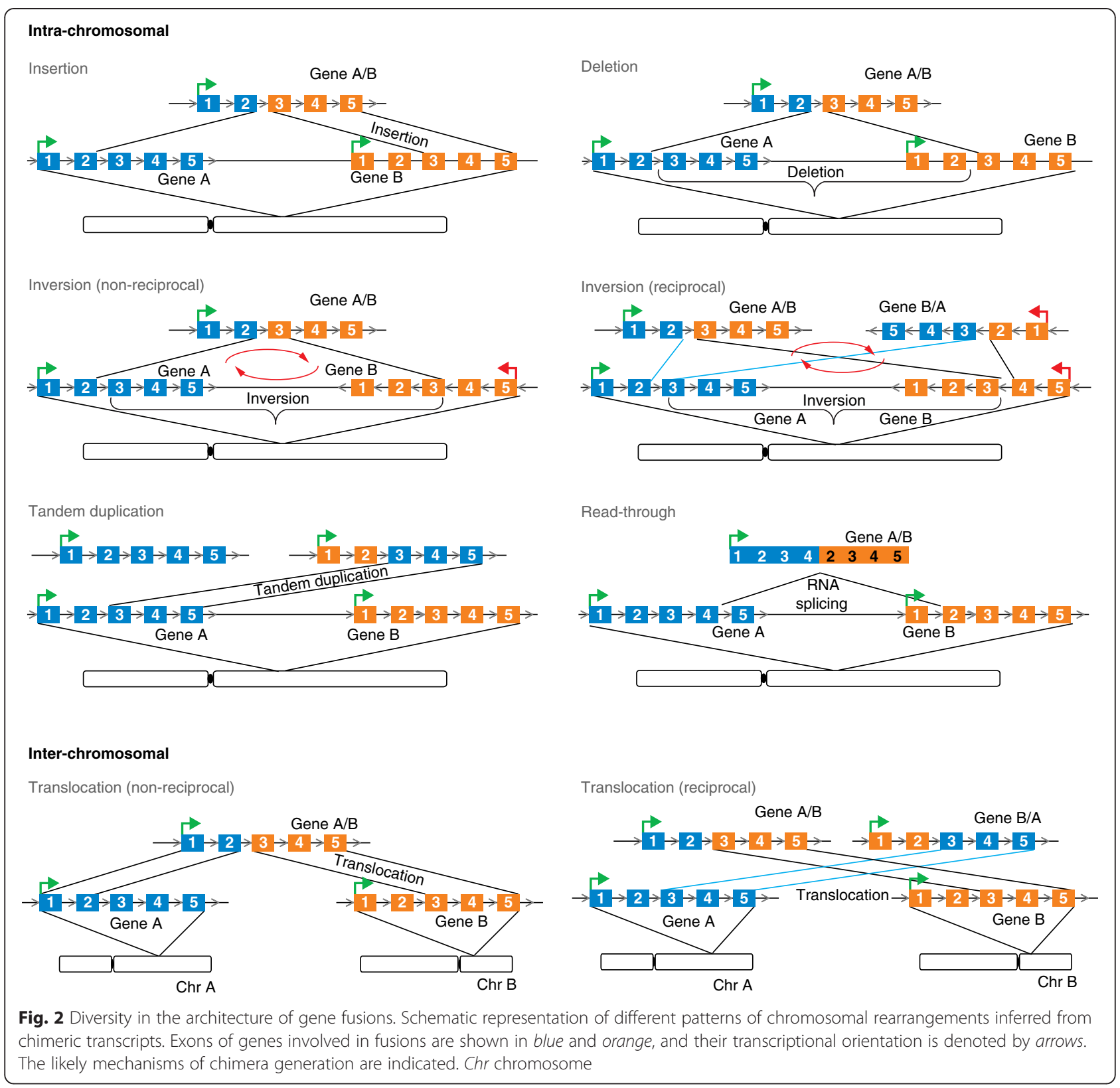

growth and proliferation. TFE3 is involved in chromosomal translocations that result in various gene fusions (such as PRCC-TFE3, RCC17-TFE3, PSF-TFE3, NON$O(p 54 n r b)-T F E 3$ and ASPL-TFE3) in papillary renal cell carcinomas. PLAG1 is an oncogenic transcription factor associated with the neoplastic transformation of pleomorphic adenomas of the salivary gland and lipoblastomas through upregulation of IGF2, CRLF1, CRABP2, CRIP2, and PIGF. NFIB binds viral and cellular promoters activating transcription and replication. POU5F1 and PAX8 are homeobox-containing transcription factors, a family of genes that play a role in cell fate and differentiation programs, and whose role in cancer is well recognized, particularly $P A X 8$ in thyroid cancer [22].

\section{Other functional classes}

\section{Metabolic enzymes}

CD44-SLC1A2/EAAT2 gene fusions are detected in 1$2 \%$ of gastric cancers involving the glutamate transporter SLC1A2 [85], and cause intracellular accumulation of glutamate, a growth-promoting amino acid associated with oncogenic functions [97, 98]. Thus, this gene fusion may be establishing a pro-oncogenic metabolic milieu, akin to the increased levels of sarcosine reported in prostate cancer [99].

\section{Wnt/B-catenin signaling pathway}

RNA sequencing of 68 "microsatellite stable" subtype colorectal cancer samples revealed two recurrent fusions 


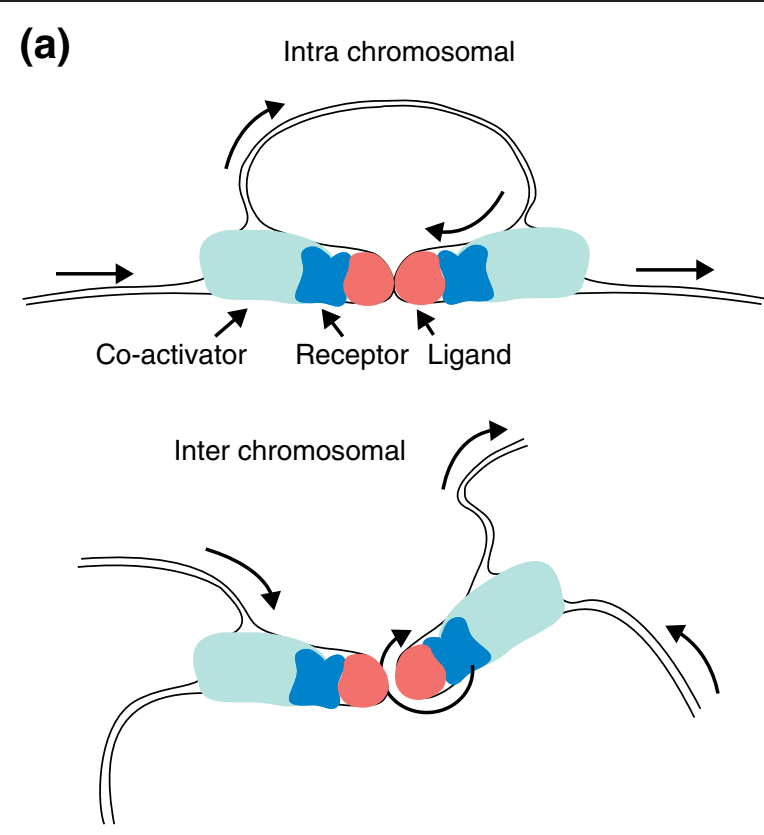

(b)

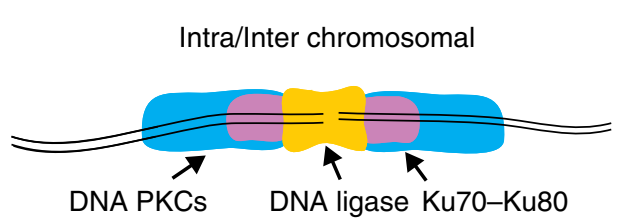

Fig. 3 Schematic illustration of the molecular mechanisms underlying the formation of gene fusions. a "Induced proximity", or chromosomal proximity induced by receptor-ligand co-activator-mediated transcription between genes on the same chromosome (intra-chromosomal) or different chromosomes (inter-chromosomal). Physical proximity accompanied by a chromosomal break during transcription or mediated by genotoxic stress can lead to aberrations in DNA repair, which, in turn, may cause the formation of gene fusions. $\mathbf{b}$ Fusions may result from aberrant DNA double-strand break repair involving alternative-non-homologous end joining machinery. PKC protein kinase C

involving R-spondin family genes, EIF3E-RSPO2 in two cases and PTPRK-RSPO3 in five cases [84]. Both these gene fusions retained the functional domain of the $R$ spondins that are known to be agonists of the canonical Wnt/ $\beta$-catenin signaling pathway. Additionally, the $L A C T B 2-N C O A 2$ chimeric transcript detected in 6 of 99 (6.1\%) colorectal cancer cases led to disruption of NCOA2 expression, thus activating the $\mathrm{Wnt} / \beta$-catenin pathway [100]. Recently, R-spondin fusions such as GRHL2-RSPO2 were described in prostate cancer as well [83].

\section{TGF- $\beta$ pathway}

Recently, fusions involving SKIL (which encodes a SMAD inhibitor) $3^{\prime}$ to androgen-regulated promoters such as TMPRSS2, SLC45A3, and ACPP, were found in 6 of $540(1.1 \%)$ prostate cancers and one cell line xenograft, LuCaP-77 [101]. SKIL overexpression in these tumors was associated with upregulation of the TGF- $\beta$ pathway, likely providing the oncogenic mechanism in these tumors.

\section{Chromatin modifier genes}

In an analysis of fusion transcripts observed in TCGA data across multiple tumor types, fusions involving chromatin modifier genes, including histone methyltransferase and histone demethylase genes, were identified in 111 samples (2.5\%) [89]. Chromatin modifier genes are potential therapeutic targets and these gene fusions thus represent a novel class of potentially actionable aberrations.

\section{Further functional classes}

Additional classes of genes represented among recurrent fusions in solid cancers include those encoding growth factor receptors (GABBR2, TACSTD2, ITPR2), adaptors and co-factors (WIF1, GAB2), Ras-Gap proteins (DOCK5, $A R H G A P 15)$, and cytoskeletal proteins (SNF8, SEC22B, HIP1R, STXBP4, MYO19, TPR). Although some of these fusions are scored as recurrent, they may represent passenger mutations associated with loci of recurrent chromosomal aberrations, while others may define tissuespecific or cooperative roles. 


\section{Loss-of-function gene fusions}

While most reported gene fusions pertain to gain-offunction aberrations imparting neoplastic phenotypes, with high-throughput sequencing, fusions resulting in loss of function of tumor suppressors such as TP53 and PTEN have been identified as well [102]. The LACTB2-NCOA2 fusion in colorectal cancer leads to disruption of NCOA2, which encodes an inhibitor of the $\mathrm{Wnt} / \beta$-catenin pathway [100], thus acting to promote carcinogenesis.

\section{Gene fusion signatures in personalized medicine of epithelial cancers}

Some gene fusions are associated with distinct subtypes of carcinoma, while others have been detected across different tissues or lineages, defining molecular subsets of cancers transcending morphological distinctions.

\section{Recurrent gene fusions as biomarkers of subtypes of solid cancers}

Some of the salient gene fusions that define molecular subtypes of epithelial cancers within specific organs or tissue types are summarized in Table 1. The ETV6NTRK3 fusion is a diagnostic biomarker of secretory breast carcinoma, as well as the acinic cell carcinoma or cystadenocarcinoma recently designated as "mammary analog secretory carcinoma of salivary glands" (MASC) $[21,103]$. BRD-NUT fusions define NUT midline carcinoma $[104,105]$. CRTC-MAML2 fusions are the defining molecular aberration of mucoepidermoid carcinoma (MEC) [106, 107]; translocation-negative MECs are proposed to be designated as a distinct subgroup of adenosquamous carcinoma [108]. CRTC-MAML fusions are also found in MEC of the lung [109-112], cervix [113], thyroid glands and oral cavity [114], as well as in clear cell hidradenoma of the skin $[115,116]$. In all cases, $M A M L 2$ fusions characterize benign or low-grade tumors, and for reasons not described so far have been associated with a favorable prognosis [117]. Interestingly, pulmonary MECs have shown clinical response to gefitinib in the absence of sensitizing EGFR mutations, suggesting a potential connection with CRTC-MAML2 and the possibility of therapeutic application in other MECs harboring this fusion $[110,118]$. The diagnostic subclass of adenoid cystic carcinomas, including salivary gland and breast cancer, is characterized by $M Y B-N F I B$ gene fusions [119, 120]. Fusions defining subtypes within a cancer include RET and NTRK gene fusions in subsets of papillary thyroid carcinoma [121], while $P A X 8-P P A R \gamma$ fusions characterize subsets of follicular thyroid carcinoma [22, 122]. ETS family gene fusions, primarily including ERG (and less frequently, ETV1, ETV4, ETV5 or FLI1), are found in approximately $50 \%$ of prostate cancers, the most common fusion being TMPRSS2-ERG. The EWSR1-ATF1 fusion found in hyalinizing clear cell carcinoma of the salivary glands, a rare and indolent tumor, can potentially be used as a molecular marker of this subtype that is histologically similar to the more aggressive MEC [123].

Gene fusions or fusion partners found across tissue types are common in solid cancers. The EML4-ALK fusion, initially identified in lung cancer $[9,10]$ has since been reported in breast cancer [124], colorectal carcinomas $[66,124]$, and in pediatric renal medullary carcinoma that affects young African-Americans with the sickle cell trait $[125,126]$. Similarly, RET fusions, first characterized in thyroid cancer, are widely observed in lung cancers, and the EWSR1-POU5F1 fusion was detected in two rare epithelial tumors, hidradenoma of the skin and MEC of the salivary glands [127].

Gene fusions involving RAF kinase genes (BRAF, $R A F 1, C R A F)$ have been identified in low-grade tumors of the central nervous system (pilocytic astrocytomas and other low-grade gliomas), gastric cancer, melanoma and prostate cancer. RAF family fusions involve truncation of the $\mathrm{N}$-terminal auto-inhibitory domain, thus generating constitutively active RAF protein. Curiously, BRAF gene fusions in low-grade astrocytomas have been associated with a tendency to growth arrest, conferring a less aggressive clinical phenotype and a better clinical outcome [75, 128]. Additionally, RAF family fusions have been defined across diverse solid cancers, including prostate, gastric, and skin cancers [82, 83]. A screen for $B R A F$ gene fusions in 20,573 solid tumors, using the FoundationOne $^{\mathrm{TM}}$ targeted gene panel, identified $B R A F$ fusions involving 29 unique $5^{\prime}$ fusion partners in 55 $(0.3 \%)$ cases across 12 different tumor types, including $3 \%(14 / 531)$ of melanomas, $2 \%(15 / 701)$ of gliomas, $1.0 \%(3 / 294)$ of thyroid cancers, $0.3 \%(3 /$ $1,062)$ of pancreatic carcinomas, $0.2 \%(8 / 4,013)$ of non-small cell lung cancers and $0.2 \%(4 / 2,154)$ of colorectal cancers, as well as single cases of head and neck cancer, prostate cancer, rectal adenocarcinoma, ovarian, uterine endometrial, and mesothelioma [70].

Fusions involving FGFR tyrosine kinase family genes have also been observed across diverse cancers [88]. The first FGFR fusion observed in epithelial cancers, FGFR1PLAG1, was found in a subset of pleomorphic salivary gland adenomas, and involves FGFR1 as the $5^{\prime}$ partner upstream of PLAG1, the known driver of salivary gland tumors [91]. Curiously, this fusion excludes the tyrosine kinase domain of FGFR. Fusions that retain the tyrosine kinase domain of FGFR include FGFR3-TACC3 in glioblastoma [92, 129]. Subsequently, diverse FGFR fusions, all retaining the tyrosine kinase domain, have been observed in bladder, lung, breast, thyroid, oral, and prostate cancers, involving FGFR1, 2, or 3 either as the $5^{\prime}$ or $3^{\prime}$ partners [88, 94]. 


\section{Some gene fusions provide personalized therapeutic targets}

In Additional file 2 we summarize recent clinical trials involving gene fusions in epithelial cancers. The RET inhibitor vandetanib shows antiproliferative activity in RET-mutant medullary thyroid cancer (MTC) [130], and was recently approved by the US Food and Drug Administration for treatment of metastatic MTC. Sensitivity to vandetanib was also observed in RET-fusionpositive papillary thyroid carcinoma [131] and lung cancer cells $[68,132]$. Treatment with Pfizer's kinase inhibitor crizotinib (PF02341066) led to a dramatic clinical response in EML4-ALK-positive NSCLC patients [133, 134], as well as in one patient with an SLC34A2-ROS1fusion-positive tumor [58]. Unfortunately, resistance is inevitably observed, owing to mutations in the kinase domain [134, 135], or $A L K$ gene fusion amplification, $K I T$ amplification or increased auto-phosphorylation of EGFR [136]. This is representative of the challenge of treating solid cancers and argues for the development of combinatorial therapeutic approaches from the start rather than sequentially, as is the practice currently. RAF or MEK inhibitors represent potential precision therapeutic options for several solid cancers with the diverse RAF family gene fusions described earlier. Several FGFR inhibitors currently in clinical trials represent potential therapeutics for cancers harboring FGFR fusions across multiple cancer types, including bladder cancer, prostate cancer, and others $[88,90,94,137]$. The rare PIK3C family gene fusions in prostate cancer (for example, TBXLR1$P I K 3 C A$ and $A C P P-P I K 3 C B$ ) show overexpression of the $P I 3 K C$ genes and may be sensitive to PIK3CA inhibitors [83].

For treatment of secretory breast carcinoma expressing the ETV6-NTRK3 fusion, therapeutic targeting of the downstream signaling axis of IGF1R, using the IGIFR/INSR kinase inhibitors BMS-536924 and BMS754807 that are currently in clinical trials, was found to be effective [138]. Breast cancer cells expressing $\mathrm{NOTCH}$ fusion products that retain the $\gamma$-secretase cleavage site were sensitive to $\gamma$-secretase inhibitor (GSI) in culture, and treatment with GSI reduced tumor growth in vivo [86]. On the other hand, breast cancer cells harboring $\mathrm{NOTCH}$ fusions that encode NICD independent of the $\gamma$-secretase cleavage site were insensitive to GSI.

In a recent clinical sequencing study of 102 pediatric cancers, among 37 non-sarcoma solid cancers, several functional gene fusions were identified, including TFE3 fusions in a colorectal cancer (SFPQ-TFE3) and renal cell cancer (ASPSCR1-TFE3) - both cases were treated with pazopanib, the latter displaying stable disease for 10 months [139].

Efforts to target several other gene fusions are underway. The newly developed bromodomain inhibitors that have shown dramatic efficacy in hematological malignancies $[140,141]$ are now being tested in multiple clinical trials for NUT midline carcinoma characterized by BRD3/4-NUT gene fusions, which represent a rare but highly aggressive class of tumors with no effective treatment currently available [104]. Also, the $\mathrm{R}$-spondin fusions observed in colorectal and prostate cancer may be sensitive to Wnt pathway antagonist porcupine inhibitors [142].

Gene fusions involving ETS transcription factors have been utilized in diagnostic applications. A non-invasive assay system has been developed based on the detection of TMPRSS2-ERG fusion transcripts in urine samples from patients, which in combination with the detection of urine PCA3 improved the performance of the multivariate Prostate Cancer Prevention Trial risk calculator in predicting cancer on biopsy [143]. Detection of TMPRSS2-ERG in circulating tumor cells in therapynaive patients and in castration-resistant prostate cancer patients following treatment suggests potential applications in non-invasive monitoring of the therapeutic response [144]. While therapeutic targeting of transcription factor oncogenes is intrinsically challenging, on the basis of the interaction of ERG with the DNA repair enzyme PARP1 and DNA protein kinase DNA-PKc, use of PARP inhibitors was shown to inhibit growth of TMPRSS2-ERG-positive prostate cancer xenografts [145]. Additionally, PARP inhibition was associated with radiosensitization of TMPRSS2-ERG-positive prostate cancer cells [146, 147]. These experimental leads point to possible therapeutic avenues targeting a prevalent gene fusion in a common carcinoma.

\section{Perspectives and discussion}

Genomic or transcriptomic sequencing has virtually supplanted molecular and cytogenetic techniques as the primary modality for discovery of gene fusions, and detection of gene fusions is increasingly incorporated into the standard workflow for genomic characterization of tumors in both research and clinical settings. Transcriptome sequencing has been useful in helping to identify expressed gene fusions based on evidence of the fusion of exon boundaries, but putative promoter fusions that do not generate chimeric transcripts are likely to go undetected. Furthermore, typically recurrent gene fusions characterized in cancers represent gain-of-function events arising from the juxtaposition of cell-type- or lineage-specific regulatory elements and proto-oncogenes, or novel combinations of functional domains derived from two proteins that provide combinatorial or additive functionalities to normal genes. However, NGS data also reveal less frequently described loss-of-function chimeras involving tumor suppressor genes such as TP53, PTEN, and others. A systematic analysis of loss-of-function gene 
fusions could identify additional cancer samples with loss of tumor suppressors that might be currently going unreported, and could help broaden our understanding of the role of gene fusions in cancer.

The rapid increase in detection of gene fusions across cancers has spawned multiple discovery and prioritization pipelines to help distinguish bona fide functional gene fusions from random chimeras (and experimental artifacts). However, the development of diverse pipelines following different analysis parameters underscores a need for standardization of the vocabulary and information content in recording and reporting gene fusions, along the lines of the Minimum Information About a Microarray Experiment [148, 149]. Furthermore, even as bioinformatics analyses help prioritize fusion candidates, the "recurrence" of fusion genes and/or retention of functional domains provide the most compelling rationale for functional characterization.

The detection of distinct gene fusions across subtypes of common carcinoma also provides a basis for molecular subclassification of these cancers. Recurrent gene fusions that characterize distinct subtypes of cancers include BRD4-NUT in NUT midline carcinoma, ETV6NTRK3 in secretory breast carcinoma, CRTC-MAML2 fusions in mucoepidermoid carcinoma, and RAF family fusions in pilocytic astrocytomas. It is expected that as more and more carcinomas are analyzed by sequencing, additional subclasses may be recognized on the basis of whether the detected molecular aberrations are driver fusions. Importantly, the emerging landscape of gene fusions in solid cancers also reveals many gene fusions involving oncogene families or isoforms that are seen across multiple tumor types or subtypes, for example, fusions involving RAF and FGFR family genes. This supports the notion that a molecular classification of tumors in terms of driver fusions (or SNVs) may complement histopathological descriptions.

Many oncogenes involved in gene fusions (for example, RET, BRAF, ALK, NOTCH or PIK3CA/B) are also known to harbor activating mutations. However, fusions and mutations tend to be mutually exclusive. This indicates that either fusions or activating mutations can independently provide oncogenic function, and that either of these aberrations may render the tumors sensitive to therapeutic targeting. Thus, for example, MEK inhibitors that have been found to be useful for tumors with a $B R A F$ activating mutation may also benefit tumors with the $B R A F$ fusion.

The development of technologies that enable the systematic detection of molecular aberrations in cancer has profound clinical implications, as high-throughput sequencing of individual tumor samples is expected to become available as a routine diagnostic modality (as for whole-body PET scans or MRI) in the not-too-distant future. Considering the important diagnostic and therapeutic implications, the integration of approaches for the detection of driver gene fusions into cancer genomics pipelines is crucial for precision cancer medicine.

\section{Additional files}

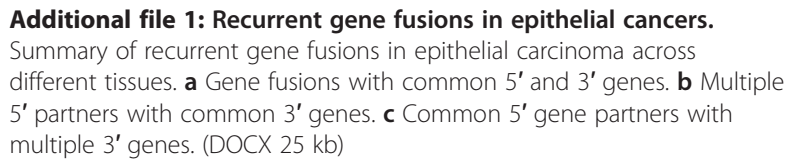

Additional file 2: Clinical trials involving gene fusions in epithelial cancers. (PDF $287 \mathrm{~kb}$ )

\section{Abbreviations}

ACC: Adenoid cystic carcinoma; ALL: Acute lymphoblastic leukemia; AML: Acute myeloid leukemia; APL: Acute promyelocytic leukemia, cholangio cholangiocarcinoma; CML: Chronic myeloid leukemia; CRC: Colorectal carcinoma; CRPC: Castration-resistant prostate cancer; EBRT: External beam radiation therapy; EBV: Epstein-Barr virus; EST: Expressed sequence tag; FDA: Food and drug administration; FTC: Follicular thyroid carcinoma; GSI: Y-secretase inhibitor; HBV: Hepatitis B virus; HCV: Hepatitis C virus; HDR: High dose rate; HPV: Human papilloma virus; KSHV: Kaposi's sarcoma-associated herpesvirus; MASC: Mammary analog secretory carcinoma of salivary glands; MCV: Molluscum contagiosum virus; MEC: Mucoepidermoid carcinoma; MLL: Mixed lineage leukemia; MTC: Medullary thyroid cancer; nccRCC: non-clear-cell renal cell carcinoma; NGS: Next-generation sequencing; NICD: NOTCH intracellular domain; NMC: NUT midline carcinoma; NSCLC: Non-small-cell lung carcinoma; ORF: Open reading frame; Ph: Philadelphia chromosome; PLGA: Pediatric low grade astrocytoma; PTC: Papillary thyroid cancer; RACE 3': Rapid amplification of CDNA ends; RCC: Renal cell carcinoma; RMC: Renal medullary carcinoma; TCGA: The Cancer Genome Atlas; TKI: Tyrosine kinase inhibitor; UTR: Untranslated region.

\section{Competing interests}

The University of Michigan has filed for a patent on recurrent gene fusions in prostate cancer and AMC is named as a co-inventor. The technology has been licensed to Hologic Inc. to develop a molecular diagnostic.

\section{Acknowledgements}

We thank Robin Kunkel for help with the artwork for the figures. AMC is supported by the Doris Duke Charitable Foundation Clinical Scientist Award and the Prostate Cancer Foundation. AMC is an American Cancer Society Research Professor and A. Alfred Taubman Scholar. This work was supported in part by the US National Institutes of Health (R01CA132874), Early Detection Research Network grant UO1 CA111275, Prostate SPORE grant P50CA69568, the Department of Defense Era of Hope grant BC075023 (AMC).

\section{Author details}

${ }^{1}$ Michigan Center for Translational Pathology, University of Michigan Medical School, Ann Arbor, Ml 48109, USA. ²Department of Pathology, University of Michigan Medical School, Ann Arbor, Ml 48109, USA. ${ }^{3}$ Department of Computational Medicine and Bioinformatics, University of Michigan Medical School, Ann Arbor, Ml 48109, USA. ${ }^{4}$ Howard Hughes Medical Institute, University of Michigan Medical School, Ann Arbor, Ml 48109, USA.

${ }^{5}$ Department of Urology, University of Michigan Medical School, Ann Arbor, Ml 48109, USA. ${ }^{6}$ Comprehensive Cancer Center, University of Michigan Medical School, Ann Arbor, MI 48109, USA.

Published online: 18 December 2015

\section{References}

1. Nowell PC, Hungerford DA. Chromosome studies on normal and leukemic human leukocytes. J Natl Cancer Inst. 1960;25:85-109.

2. Nowell PC, Hungerford DA. Chromosome studies in human leukemia. II. Chronic granulocytic leukemia. J Natl Cancer Inst. 1961;27:1013-35.

3. Wong S, Witte ON. The BCR-ABL story: bench to bedside and back. Annu Rev Immunol. 2004;22:247-306. 
4. Rabbitts TH. Commonality but diversity in cancer gene fusions. Cell. 2009; 137(3):391-5.

5. Mertens F, Johansson B, Fioretos T, Mitelman F. The emerging complexity of gene fusions in cancer. Nat Rev Cancer. 2015;15(6):371-81.

6. Mitelman F, Johansson B, Mertens F. Fusion genes and rearranged genes as a linear function of chromosome aberrations in cancer. Nat Genet. 2004; 36(4):331-4.

7. Tomlins SA, Rhodes DR, Perner S, Dhanasekaran SM, Mehra R, Sun XW, et al. Recurrent fusion of TMPRSS2 and ETS transcription factor genes in prostate cancer. Science. 2005;310(5748):644-8.

8. Tomlins SA, Laxman B, Dhanasekaran SM, Helgeson BE, Cao X, Morris DS, et al. Distinct classes of chromosomal rearrangements create oncogenic ETS gene fusions in prostate cancer. Nature. 2007;448(7153):595-9.

9. Rikova K, Guo A, Zeng Q, Possemato A, Yu J, Haack H, et al. Global survey of phosphotyrosine signaling identifies oncogenic kinases in lung cancer. Cell. 2007;131(6):1190-203.

10. Soda M, Choi YL, Enomoto M, Takada S, Yamashita Y, Ishikawa S, et al. Identification of the transforming EML4-ALK fusion gene in non-small-cell lung cancer. Nature. 2007:448(7153):561-6.

11. Mardis ER. A decade's perspective on DNA sequencing technology. Nature. 2011:470(7333):198-203.

12. Maher CA, Kumar-Sinha C, Cao X, Kalyana-Sundaram S, Han B, Jing X, et al. Transcriptome sequencing to detect gene fusions in cancer. Nature. 2009; 458(7234):97-101.

13. Maher CA, Palanisamy N, Brenner JC, Cao X, Kalyana-Sundaram S, Luo S, et al. Chimeric transcript discovery by paired-end transcriptome sequencing. Proc Natl Acad Sci U S A. 2009;106(30):12353-8.

14. Stephens PJ, McBride DJ, Lin ML, Varela I, Pleasance ED, Simpson JT, et al. Complex landscapes of somatic rearrangement in human breast cancer genomes. Nature. 2009;462(7276):1005-10.

15. Grieco M, Santoro M, Berlingieri MT, Melillo RM, Donghi R, Bongarzone I, et al. PTC is a novel rearranged form of the ret proto-oncogene and is frequently detected in vivo in human thyroid papillary carcinomas. Cell. 1990;60(4):557-63.

16. Greco A, Miranda C, Pagliardini S, Fusetti L, Bongarzone I, Pierotti MA. Chromosome 1 rearrangements involving the genes TPR and NTRK1 produce structurally different thyroid-specific TRK oncogenes. Genes Chromosomes Cancer. 1997;19(2):112-23.

17. Fusco A, Grieco M, Santoro M, Berlingieri MT, Pilotti S, Pierotti MA, et al. A new oncogene in human thyroid papillary carcinomas and their lymph-nodal metastases. Nature. 1987;328(6126):170-2.

18. Kas K, Voz ML, Roijer E, Astrom AK, Meyen E, Stenman G, et al. Promoter swapping between the genes for a novel zinc finger protein and $\beta$-catenin in pleiomorphic adenomas with $\mathrm{t}(3 ; 8)(\mathrm{p} 21 ; \mathrm{q} 12)$ translocations. Nat Genet. 1997;15(2):170-4.

19. Geurts JM, Schoenmakers EF, Roijer E, Stenman G, Van de Ven WJ. Expression of reciprocal hybrid transcripts of HMGIC and FHIT in a pleomorphic adenoma of the parotid gland. Cancer Res. 1997;57(1):13-7.

20. Sidhar SK, Clark J, Gill S, Hamoudi R, Crew AJ, Gwilliam R, et al. The t(X 1)(p11.2;q21.2) translocation in papillary renal cell carcinoma fuses a novel gene PRCC to the TFE3 transcription factor gene. Hum Mol Genet. 1996;5(9): $1333-8$.

21. Tognon C, Knezevich SR, Huntsman D, Roskelley CD, Melnyk N, Mathers JA, et al. Expression of the ETV6-NTRK3 gene fusion as a primary event in human secretory breast carcinoma. Cancer Cell. 2002;2(5):367-76.

22. Kroll TG, Sarraf P, Pecciarini L, Chen CJ, Mueller E, Spiegelman BM, et al. PAX8-PPARY1 fusion oncogene in human thyroid carcinoma. Science. 2000; 289(5483):1357-60

23. French CA, Miyoshi I, Aster JC, Kubonishi I, Kroll TG, Dal Cin P, et al. BRD4 bromodomain gene rearrangement in aggressive carcinoma with translocation $\mathrm{t}(15 ; 19)$. Am J Pathol. 2001;159(6):1987-92.

24. Kumar-Sinha C, Tomlins SA, Chinnaiyan AM. Recurrent gene fusions in prostate cancer. Nat Rev Cancer. 2008;8(7):497-511.

25. Boveri T. Zur Frage der Entstehung maligner Tumoren. Gustav Fisher: Jena; 1914.

26. Inaki K, Hillmer AM, Ukil L, Yao F, Woo XY, Vardy LA, et al. Transcriptional consequences of genomic structural aberrations in breast cancer. Genome Res. 2011;21(5):676-87.

27. Yao F, Kausalya JP, Sia YY, Teo AS, Lee WH, Ong AG, et al. Recurrent fusion genes in gastric cancer: CLDN18-ARHGAP26 induces loss of epithelial integrity. Cell Rep. 2015;12(2):272-85.
28. Dillon R, Nilsson CL, Shi SD, Lee NV, Krastins B, Greig MJ. Discovery of a novel B-Raf fusion protein related to c-Met drug resistance. J Proteome Res. 2011;10(11):5084-94.

29. Kumar-Sinha C, Kalyana-Sundaram S, Chinnaiyan AM. SLC45A3-ELK4 chimera in prostate cancer: spotlight on cis-splicing. Cancer Discov. 2012;2(7):582-5.

30. Rickman DS, Pflueger D, Moss B, VanDoren VE, Chen CX, de la Taille A, et al. SLC45A3-ELK4 is a novel and frequent erythroblast transformation-specific fusion transcript in prostate cancer. Cancer Res. 2009;69(7):2734-8.

31. Zhang $Y$, Gong M, Yuan H, Park HG, Frierson HF, Li H. Chimeric transcript generated by cis-splicing of adjacent genes regulates prostate cancer cell proliferation. Cancer Discov. 2012;2(7):598-607.

32. Bass AJ, Lawrence MS, Brace LE, Ramos AH, Drier $Y$, Cibulskis $K$, et al. Genomic sequencing of colorectal adenocarcinomas identifies a recurrent VTI1A-TCF7L2 fusion. Nat Genet. 2011;43(10):964-8.

33. Nome T, Hoff AM, Bakken AC, Rognum TO, Nesbakken A, Skotheim RI. High frequency of fusion transcripts involving TCF7L2 in colorectal cancer: novel fusion partner and splice variants. PLoS One. 2014;9(3), e91264.

34. Guerra E, Trerotola M, Dell' Arciprete R, Bonasera V, Palombo B, El-Sewedy T, et al. A bicistronic CYCLIN D1-TROP2 mRNA chimera demonstrates a novel oncogenic mechanism in human cancer. Cancer Res. 2008;68(19):8113-21.

35. Iyer MK, Chinnaiyan AM, Maher CA. ChimeraScan: a tool for identifying chimeric transcription in sequencing data. Bioinformatics. 2011;27(20):2903-4.

36. Sboner A, Habegger L, Pflueger D, Terry S, Chen DZ, Rozowsky JS, et al. FusionSeq: a modular framework for finding gene fusions by analyzing paired-end RNA-sequencing data. Genome Biol. 2010;11(10):R104.

37. McPherson A, Hormozdiari F, Zayed A, Giuliany R, Ha G, Sun MG, et al. deFuse: an algorithm for gene fusion discovery in tumor RNA-Seq data. PLoS Comput Biol. 2011;7(5):e1001138.

38. Kim D, Salzberg SL. TopHat-Fusion: an algorithm for discovery of novel fusion transcripts. Genome Biol. 2011;12(8):R72.

39. Torres-Garcia W, Zheng S, Sivachenko A, Vegesna R, Wang Q, Yao R, et al. PRADA: pipeline for RNA sequencing data analysis. Bioinformatics. 2014; 30(15):2224-6

40. Davidson NM, Majewski IJ, Oshlack A. JAFFA: high sensitivity transcriptomefocused fusion gene detection. Genome Med. 2015;7(1):43.

41. Lira ME, Choi YL, Lim SM, Deng S, Huang D, Ozeck M, et al. A single-tube multiplexed assay for detecting ALK, ROS1, and RET fusions in lung cancer J Mol Diagn. 2014;16(2):229-43.

42. Lira ME, Kim TM, Huang D, Deng S, Koh Y, Jang B, et al. Multiplexed gene expression and fusion transcript analysis to detect ALK fusions in lung cancer. J Mol Diagn. 2013;15(1):51-61.

43. Suehara Y, Arcila M, Wang L, Hasanovic A, Ang D, Ito T, et al. Identification of KIF5B-RET and GOPC-ROS1 fusions in lung adenocarcinomas through a comprehensive mRNA-based screen for tyrosine kinase fusions. Clin Cancer Res. 2012;18(24):6599-608.

44. Mitelman F. Recurrent chromosome aberrations in cancer. Mutat Res. 2000 462(2-3):247-53.

45. Mitelman F, Johansson B, Mertens FE. Mitelman Database of Chromosome Aberrations and Gene Fusions in Cancer. Cancer Genome Anatomy Project; 2014. http://cgap.nci.nih.gov/Chromosomes/Mitelman.

46. Tomlins SA, Laxman B, Varambally S, Cao X, Yu J, Helgeson BE, et al. Role of the TMPRSS2-ERG gene fusion in prostate cancer. Neoplasia. 2008;10(2):177-8.

47. Cerveira N, Ribeiro FR, Peixoto A, Costa V, Henrique R, Jeronimo C, et al. TMPRSS2-ERG gene fusion causing ERG overexpression precedes chromosome copy number changes in prostate carcinomas and paired HGPIN lesions. Neoplasia. 2006;8(10):826-32.

48. Tu JJ, Rohan S, Kao J, Kitabayashi N, Mathew S, Chen YT. Gene fusions between TMPRSS2 and ETS family genes in prostate cancer: frequency and transcript variant analysis by RT-PCR and FISH on paraffin-embedded tissues. Mod Pathol. 2007;20(9):921-8.

49. Attard G, Clark J, Ambroisine L, Fisher G, Kovacs G, Flohr P, et al. Duplication of the fusion of TMPRSS2 to ERG sequences identifies fatal human prostate cancer. Oncogene. 2008;27(3):253-63.

50. Mehra R, Tomlins SA, Yu J, Cao X, Wang L, Menon A, et al. Characterization of TMPRSS2-ETS gene aberrations in androgen-independent metastatic prostate cancer. Cancer Res. 2008:68(10):3584-90.

51. Perner S, Svensson MA, Hossain RR, Day JR, Groskopf J, Slaughter RC, et al. ERG rearrangement metastasis patterns in locally advanced prostate cancer. Urology. 2010;75(4):762-7. 
52. Klezovitch O, Risk M, Coleman I, Lucas JM, Null M, True LD, et al. A causal role for ERG in neoplastic transformation of prostate epithelium. Proc Natl Acad Sci U S A. 2008;105(6):2105-10.

53. Han B, Mehra R, Dhanasekaran SM, Yu J, Menon A, Lonigro RJ, et al. A fluorescence in situ hybridization screen for E26 transformation-specific aberrations: identification of DDX5-ETV4 fusion protein in prostate cancer. Cancer Res. 2008;68(18):7629-37.

54. Tomlins SA, Mehra R, Rhodes DR, Smith LR, Roulston D, Helgeson BE, et al. TMPRSS2:ETV4 gene fusions define a third molecular subtype of prostate cancer. Cancer Res. 2006:66(7):3396-400.

55. Helgeson BE, Tomlins SA, Shah N, Laxman B, Cao Q, Prensner JR, et al. Characterization of TMPRSS2:ETV5 and SLC45A3:ETV5 gene fusions in prostate cancer. Cancer Res. 2008;68(1):73-80.

56. Paulo P, Barros-Silva JD, Ribeiro FR, Ramalho-Carvalho J, Jeronimo C, Henrique R, et al. FLI1 is a novel ETS transcription factor involved in gene fusions in prostate cancer. Genes Chromosomes Cancer. 2012;51(3):240-9.

57. Takeuchi K, Choi YL, Togashi Y, Soda M, Hatano S, Inamura K, et al KIF5B-ALK, a novel fusion oncokinase identified by an immunohistochemistry based diagnostic system for ALK-positive lung cancer. Clin Cancer Res. 2009; 15(9):3143-9.

58. Bergethon K, Shaw AT, Ignatius Ou SH, Katayama R, Lovly CM, McDonald NT, et al. ROS1 rearrangements define a unique molecular class of lung cancers. J Clin Oncol. 2012;30:863-70.

59. Perner S, Wagner PL, Demichelis F, Mehra R, Lafargue CJ, Moss BJ, et al. EML4-ALK fusion lung cancer: a rare acquired event. Neoplasia. 2008;10(3): 298-302.

60. Kimura H, Nakajima T, Takeuchi K, Soda M, Mano H, lizasa T, et al. ALK fusion gene positive lung cancer and 3 cases treated with an inhibitor for ALK kinase activity. Lung Cancer. 2012;75(1):66-72.

61. Takahashi T, Sonobe M, Kobayashi M, Yoshizawa A, Menju T, Nakayama E, et al. Clinicopathologic features of non-small-cell lung cancer with EML4ALK fusion gene. Ann Surg Oncol. 2010;17(3):889-97.

62. Shaw AT, Yeap BY, Mino-Kenudson M, Digumarthy SR, Costa DB, Heist RS, et al. Clinical features and outcome of patients with non-small-cell lung cancer who harbor EML4-ALK. J Clin Oncol. 2009;27(26):4247-53.

63. Inamura $K$, Takeuchi $K$, Togashi $Y$, Hatano S, Ninomiya H, Motoi N, et al. EML4-ALK lung cancers are characterized by rare other mutations, a TTF-1 cell lineage, an acinar histology, and young onset. Mod Pathol. 2009;22(4): 508-15

64. Ju YS, Lee WC, Shin JY, Lee S, Bleazard T, Won JK, et al. Fusion of KIF5B and RET transforming gene in lung adenocarcinoma revealed from wholegenome and transcriptome sequencing. Genome Res. 2011:22:436-45.

65. Takeuchi K, Soda M, Togashi Y, Suzuki R, Sakata S, Hatano S, et al. RET, ROS1 and ALK fusions in lung cancer. Nat Med. 2012;18:378-81.

66. Lipson D, Capelletti M, Yelensky R, Otto G, Parker A, Jarosz M, et al. Identification of new ALK and RET gene fusions from colorectal and lung cancer biopsies. Nat Med. 2012;18:382-4.

67. Kohno T, Ichikawa H, Totoki Y, Yasuda K, Hiramoto M, Nammo T, et al. KIF5B-RET fusions in lung adenocarcinoma. Nat Med. 2012;18:375-7.

68. Drilon A, Wang L, Hasanovic A, Suehara Y, Lipson D, Stephens P, et al. Response to cabozantinib in patients with RET fusion-positive lung adenocarcinomas. Cancer Discov. 2013;3(6):630-5.

69. Falchook GS, Ordonez NG, Bastida CC, Stephens PJ, Miller VA, Gaido L, et al. Effect of the RET inhibitor Vandetanib in a patient with RET fusion-positive metastatic non-small-cell lung cancer. J Clin Oncol. 2014. doi: 10.1200/JCO. 2013.50 .5016

70. Ross JS, Wang K, Chmielecki J, Gay L, Johnson A, Chudnovsky J, et al. The distribution of BRAF gene fusions in solid tumors and response to targeted therapy. Int J Cancer. 2015. doi: 10.1002/ijc.29825.

71. Bao ZS, Chen HM, Yang MY, Zhang CB, Yu K, Ye WL, et al. RNA-seq of 272 gliomas revealed a novel, recurrent PTPRZ1-MET fusion transcript in secondary glioblastomas. Genome Res. 2014;24(11):1765-73.

72. Lin A, Rodriguez FJ, Karajannis MA, Williams SC, Legault G, Zagzag D, et al. BRAF alterations in primary glial and glioneuronal neoplasms of the centra nervous system with identification of 2 novel KIAA1549: BRAF fusion variants. J Neuropathol Exp Neurol. 2012;71(1):66-72

73. Tian Y, Rich BE, Vena N, Craig JM, Macconaill LE, Rajaram V, et al. Detection of KIAA1549-BRAF fusion transcripts in formalin-fixed paraffin-embedded pediatric low-grade gliomas. J Mol Diagn. 2011;13(6):669-77.

74. Lawson AR, Hindley GF, Forshew T, Tatevossian RG, Jamie GA, Kelly GP, et al. RAF gene fusion breakpoints in pediatric brain tumors are characterized by significant enrichment of sequence microhomology. Genome Res. 2011; 21(4):505-14.

75. Hawkins C, Walker E, Mohamed N, Zhang C, Jacob K, Shirinian M, et al BRAF-KIAA1549 fusion predicts better clinical outcome in pediatric low-grade astrocytoma. Clin Cancer Res. 2011;17(14):4790-8.

76. Cin $H$, Meyer $\mathrm{C}$, Herr $\mathrm{R}$, Janzarik WG, Lambert S, Jones DT, et al. Oncogenic FAM131B-BRAF fusion resulting from 7q34 deletion comprises an alternative mechanism of MAPK pathway activation in pilocytic astrocytoma. Acta Neuropathol. 2011;121(6):763-74.

77. Jeuken JW, Wesseling P. MAPK pathway activation through BRAF gene fusion in pilocytic astrocytomas; a novel oncogenic fusion gene with diagnostic, prognostic, and therapeutic potential. J Pathol. 2010;222(4): 324-8.

78. Sievert AJ, Jackson EM, Gai X, Hakonarson H, Judkins AR, Resnick AC, et al. Duplication of 7q34 in pediatric low-grade astrocytomas detected by highdensity single-nucleotide polymorphism-based genotype arrays results in a novel BRAF fusion gene. Brain Pathol. 2009;19(3):449-58.

79. Jones DT, Kocialkowski S, Liu L, Pearson DM, Ichimura K, Collins VP. Oncogenic RAF1 rearrangement and a novel BRAF mutation as alternatives to KIAA1549:BRAF fusion in activating the MAPK pathway in pilocytic astrocytoma. Oncogene. 2009;28(20):2119-23.

80. Jones DT, Kocialkowski S, Liu L, Pearson DM, Backlund LM, Ichimura K, et al. Tandem duplication producing a novel oncogenic BRAF fusion gene defines the majority of pilocytic astrocytomas. Cancer Res. 2008;68(21):8673-77.

81. Berger MF, Levin JZ, Vijayendran K, Sivachenko A, Adiconis X, Maguire J, et al. Integrative analysis of the melanoma transcriptome. Genome Res. 2010; 20(4):413-27.

82. Palanisamy N, Ateeq B, Kalyana-Sundaram S, Pflueger D, Ramnarayanan K, Shankar S, et al. Rearrangements of the RAF kinase pathway in prostate cancer, gastric cancer and melanoma. Nat Med. 2010;16(7):793-8.

83. Robinson D, Van Allen EM, Wu YM, Schultz N, Lonigro RJ, Mosquera JM, et al. Integrative clinical genomics of advanced prostate cancer. Cell. 2015; 161(5):1215-28.

84. Seshagiri S, Stawiski EW, Durinck S, Modrusan Z, Storm EE, Conboy CB, et al. Recurrent R-spondin fusions in colon cancer. Nature. 2012;488(7413):660-4.

85. Tao J, Deng NT, Ramnarayanan K, Huang B, Oh HK, Leong SH, et al. CD44SLC1A2 gene fusions in gastric cancer. Sci Transl Med. 2011;3(77):77ra30.

86. Robinson DR, Kalyana-Sundaram S, Wu YM, Shankar S, Cao X, Ateeq B, et al. Functionally recurrent rearrangements of the MAST kinase and Notch gene families in breast cancer. Nat Med. 2011;17(12):1646-51.

87. Durinck S, Stawiski EW, Pavia-Jimenez A, Modrusan Z, Kapur P, Jaiswal BS, et al. Spectrum of diverse genomic alterations define non-clear cell renal carcinoma subtypes. Nat Genet. 2015;47:13-21.

88. Wu YM, Su F, Kalyana-Sundaram S, Khazanov N, Ateeq B, Cao X, et al. Identification of targetable FGFR gene fusions in diverse cancers. Cancer Discov. 2013;3(6):636-47.

89. Yoshihara K, Wang Q, Torres-Garcia W, Zheng S, Vegesna R, Kim H, et al. The landscape and therapeutic relevance of cancer-associated transcript fusions. Oncogene. 2015;34:4845-54.

90. Parker BC, Engels M, Annala M, Zhang W. Emergence of FGFR family gene fusions as therapeutic targets in a wide spectrum of solid tumours. J Pathol. 2014;232(1):4-15.

91. Persson F, Winnes M, Andren Y, Wedell B, Dahlenfors R, Asp J, et al. Highresolution array $\mathrm{CGH}$ analysis of salivary gland tumors reveals fusion and amplification of the FGFR1 and PLAG1 genes in ring chromosomes. Oncogene. 2008;27(21):3072-80.

92. Singh D, Chan JM, Zoppoli P, Niola F, Sullivan R, Castano A, et al. Transforming fusions of FGFR and TACC genes in human glioblastoma. Science. 2012; 337(6099):1231-5.

93. Weiss J, Sos ML, Seidel D, Peifer M, Zander T, Heuckmann JM, et al. Frequent and focal FGFR1 amplification associates with therapeutically tractable FGFR1 dependency in squamous cell lung cancer. Sci Transl Med. 2010;2(62):62ra93.

94. Williams SV, Hurst CD, Knowles MA. Oncogenic FGFR3 gene fusions in bladder cancer. Hum Mol Genet. 2013;22(4):795-803.

95. Medves S, Demoulin JB. Tyrosine kinase gene fusions in cancer: translating mechanisms into targeted therapies. J Cell Mol Med. 2011;16:237-48.

96. Clark JP, Cooper CS. ETS gene fusions in prostate cancer. Nat Rev Urol. 2009; 6(8):429-39.

97. Cavalheiro EA, Olney JW. Glutamate antagonists: deadly liaisons with cancer. Proc Natl Acad Sci U S A. 2001;98(11):5947-8. 
98. Rzeski W, Turski L, Ikonomidou C. Glutamate antagonists limit tumor growth. Proc Natl Acad Sci U S A. 2001;98(11):6372-7.

99. Sreekumar A, Poisson LM, Rajendiran TM, Khan AP, Cao Q, Yu J, et al. Metabolomic profiles delineate potential role for sarcosine in prostate cancer progression. Nature. 2009;457(7231):910-4.

100. Yu J, Wu WK, Liang Q, Zhang N, He J, Li X, et al. Disruption of NCOA2 by recurrent fusion with LACTB2 in colorectal cancer. Oncogene. 2015. doi: 10.1038/onc.2015.72

101. Annala M, Kivinummi K, Tuominen J, Karakurt S, Granberg K, Latonen L, et al. Recurrent SKIL-activating rearrangements in ETS-negative prostate cancer. Oncotarget. 2015;6(8):6235-50.

102. Berger MF, Lawrence MS, Demichelis F, Drier Y, Cibulskis K, Sivachenko AY, et al. The genomic complexity of primary human prostate cancer. Nature. 2011:470(7333):214-20.

103. Skalova A, Vanecek T, Sima R, Laco J, Weinreb I, Perez-Ordonez B, et al. Mammary analogue secretory carcinoma of salivary glands, containing the ETV6-NTRK3 fusion gene: a hitherto undescribed salivary gland tumor entity. Am J Surg Pathol. 2010;34(5):599-608.

104. French CA. Pathogenesis of NUT midline carcinoma. Annu Rev Pathol. 2012;7:247-65.

105. French CA, Rahman S, Walsh EM, Kuhnle S, Grayson AR, Lemieux ME, et al. NSD3-NUT fusion oncoprotein in NUT midline carcinoma: implications for a novel oncogenic mechanism. Cancer Discov. 2014:4(8):928-41.

106. Fehr A, Roser K, Belge G, Loning T, Bullerdiek J. A closer look at Warthin tumors and the $t(11 ; 19)$. Cancer Genet Cytogenet. 2008;180(2):135-9.

107. Martins C, Cavaco B, Tonon G, Kaye FJ, Soares J, Fonseca I. A study of MECT1-MAML2 in mucoepidermoid carcinoma and Warthin's tumor of salivary glands. J Mol Diagn. 2004;6(3):205-10.

108. Seethala RR, Dacic S, Cieply K, Kelly LM, Nikiforova MN. A reappraisal of the MECT1/MAML2 translocation in salivary mucoepidermoid carcinomas. Am J Surg Pathol. 2010;34(8):1106-21.

109. Achcar Rde O, Nikiforova MN, Dacic S, Nicholson AG, Yousem SA. Mammalian mastermind like 211 q21 gene rearrangement in bronchopulmonary mucoepidermoid carcinoma. Hum Pathol. 2009:40(6):854-60.

110. O'Neill ID. Gefitinib as targeted therapy for mucoepidermoid carcinoma of the lung: possible significance of CRTC1-MAML2 oncogene. Lung Cancer. 2009;64(1):129-30.

111. O'Neill ID. t(11;19) translocation and CRTC1-MAML2 fusion oncogene in mucoepidermoid carcinoma. Oral Oncol. 2009;45(1):2-9.

112. Serra A, Schackert HK, Mohr B, Weise A, Liehr T, Fitze G. t(11;19)(q21;p12 p13.11) and MECT1-MAML2 fusion transcript expression as a prognostic marker in infantile lung mucoepidermoid carcinoma. J Pediatr Surg. 2007; 42(7):E23-29.

113. Lennerz JK, Perry A, Mills JC, Huettner PC, Pfeifer JD. Mucoepidermoid carcinoma of the cervix: another tumor with the $t(11 ; 19)$-associated CRTC1-MAML2 gene fusion. Am J Surg Pathol. 2009;33(6):835-43.

114. Tirado Y, Williams MD, Hanna EY, Kaye FJ, Batsakis JG, El-Naggar AK. CRTC1/ MAML2 fusion transcript in high grade mucoepidermoid carcinomas of salivary and thyroid glands and Warthin's tumors: implications for histogenesis and biologic behavior. Genes Chromosomes Cancer. 2007:46(7):708-15.

115. Kazakov DV, Vanecek T, Belousova IE, Mukensnabl P, Kollertova D, Michal M. Skin-type hidradenoma of the breast parenchyma with $t(11 ; 19)$ translocation: hidradenoma of the breast. Am J Dermatopathol. 2007:29(5):457-61.

116. Winnes M, Molne L, Suurkula M, Andren Y, Persson F, Enlund F, et al. Frequent fusion of the CRTC1 and MAML2 genes in clear cell variants of cutaneous hidradenomas. Genes Chromosomes Cancer. 2007;46(6):559-63.

117. Nakayama T, Miyabe S, Okabe M, Sakuma H, ljichi K, Hasegawa Y, et al. Clinicopathological significance of the CRTC3-MAML2 fusion transcript in mucoepidermoid carcinoma. Mod Pathol. 2009;22(12):1575-81.

118. Han SW, Kim HP, Jeon YK, Oh DY, Lee SH, Kim DW, et al. Mucoepidermoid carcinoma of lung: potential target of EGFR-directed treatment. Lung Cancer. 2008;61(1):30-4.

119. Marchio C, Weigelt B, Reis-Filho JS. Adenoid cystic carcinomas of the breast and salivary glands (or 'The strange case of Dr Jekyll and Mr Hyde' of exocrine gland carcinomas). J Clin Pathol. 2010;63(3):220-8.

120. Persson M, Andren Y, Mark J, Horlings HM, Persson F, Stenman G. Recurrent fusion of MYB and NFIB transcription factor genes in carcinomas of the breast and head and neck. Proc Natl Acad Sci U S A. 2009;106(44):18740-4.

121. Leeman-Neill RJ, Kelly LM, Liu P, Brenner AV, Little MP, Bogdanova TI, et al. ETV6-NTRK3 is a common chromosomal rearrangement in radiationassociated thyroid cancer. Cancer. 2014;120(6):799-807.
122. Boos LA, Dettmer M, Schmitt A, Rudolph T, Steinert H, Moch H, et al. Diagnostic and prognostic implications of the PAX8-PPARY translocation in thyroid carcinomas-a TMA-based study of 226 cases. Histopathology. 2013;63(2):234-41.

123. Antonescu CR, Katabi N, Zhang L, Sung YS, Seethala RR, Jordan RC, et al. EWSR1-ATF1 fusion is a novel and consistent finding in hyalinizing clear-cell carcinoma of salivary gland. Genes Chromosomes Cancer. 2011;50(7):559-70.

124. Lin E, Li L, Guan Y, Soriano R, Rivers CS, Mohan S, et al. Exon array profiling detects EML4-ALK fusion in breast, colorectal, and non-small cell lung cancers. Mol Cancer Res. 2009;7(9):1466-76.

125. Marino-Enriquez A, Ou WB, Weldon CB, Fletcher JA, Perez-Atayde AR. ALK rearrangement in sickle cell trait-associated renal medullary carcinoma. Genes Chromosomes Cancer. 2011;50(3):146-53.

126. Debelenko LV, Raimondi SC, Daw N, Shivakumar BR, Huang D, Nelson M et al. Renal cell carcinoma with novel VCL-ALK fusion: new representative of ALK-associated tumor spectrum. Mod Pathol. 2011;24(3):430-42.

127. Moller E, Stenman G, Mandahl N, Hamberg H, Molne L, van den Oord JJ, et al. POU5F1, encoding a key regulator of stem cell pluripotency, is fused to EWSR1 in hidradenoma of the skin and mucoepidermoid carcinoma of the salivary glands. J Pathol. 2008;215(1):78-86.

128. Dessars B, De Raeve LE, El Housni H, Debouck CJ, Sidon PJ, Morandini R, et al. Chromosomal translocations as a mechanism of BRAF activation in two cases of large congenital melanocytic nevi. J Invest Dermatol. 2007; 127(6):1468-70.

129. Parker BC, Annala MJ, Cogdell DE, Granberg KJ, Sun Y, Ji P, et al. The tumorigenic FGFR3-TACC3 gene fusion escapes miR-99a regulation in glioblastoma. J Clin Invest. 2013;123(2):855-65.

130. Vitagliano D, De Falco V, Tamburrino A, Coluzzi S, Troncone G, Chiappetta G, et al. The tyrosine kinase inhibitor ZD6474 blocks proliferation of RET mutant medullary thyroid carcinoma cells. Endocr Relat Cancer. 2011;18(1):1-11.

131. Houvras Y. Completing the arc: targeted Inhibition of RET in medullary thyroid cancer. J Clin Oncol. 2012;30(2):200-2.

132. Gautschi O, Zander T, Keller FA, Strobel K, Hirschmann A, Aebi S, et al. A patient with lung adenocarcinoma and RET fusion treated with vandetanib. J Thorac Oncol. 2013;8(5):e43-4.

133. Gerber DE, Minna JD. ALK inhibition for non-small cell lung cancer: from discovery to therapy in record time. Cancer Cell. 2010;18(6):548-51.

134. Choi YL, Soda M, Yamashita Y, Ueno T, Takashima J, Nakajima T, et al. EML4ALK mutations in lung cancer that confer resistance to ALK inhibitors. N Engl J Med. 2010;363(18):1734-9.

135. Katayama R, Khan TM, Benes C, Lifshits E, Ebi H, Rivera VM, et al. Therapeutic strategies to overcome crizotinib resistance in non-small cell lung cancers harboring the fusion oncogene EML4-ALK. Proc Natl Acad Sci U S A. 2011; 108(18):7535-40

136. Katayama R, Shaw AT, Khan TM, Mino-Kenudson M, Solomon BJ, Halmos B, et al. Mechanisms of acquired crizotinib resistance in ALK-rearranged lung cancers. Sci Transl Med. 2012;4:120ra17.

137. Acquaviva J, He S, Zhang C, Jimenez JP, Nagai M, Sang J, et al. FGFR3 translocations in bladder cancer: differential sensitivity to HSP90 inhibition based on drug metabolism. Mol Cancer Res. 2014;12(7):1042-54.

138. Tognon CE, Somasiri AM, Evdokimova VE, Trigo G, Uy EE, Melnyk N, et al. ETV6-NTRK3-mediated breast epithelial cell transformation is blocked by targeting the IGF1R signaling pathway. Cancer Res. 2011;71(3):1060-70.

139. Mody RJ, Wu YM, Lonigro RJ, Cao X, Roychowdhury S, Vats P, et al. Integrative clinical sequencing in the management of refractory or relapsed cancer in youth. JAMA. 2015;314(9):913-25.

140. Dawson MA, Prinjha RK, Dittmann A, Giotopoulos G, Bantscheff M, Chan WI, et al. Inhibition of BET recruitment to chromatin as an effective treatment for MLL-fusion leukaemia. Nature. 2011:478(7370):529-33.

141. Delmore JE, Issa GC, Lemieux ME, Rahl PB, Shi J, Jacobs HM, et al. BET bromodomain inhibition as a therapeutic strategy to target c-Myc. Cell. 2011;146(6):904-17.

142. Liu J, Pan S, Hsieh MH, Ng N, Sun F, Wang T, et al. Targeting Wnt-driven cancer through the inhibition of Porcupine by LGK974. Proc Natl Acad Sci U S A. 2013;110(50):20224-9.

143. Tomlins SA, Aubin SM, Siddiqui J, Lonigro RJ, Sefton-Miller L, Miick S, et al. Urine TMPRSS2:ERG fusion transcript stratifies prostate cancer risk in men with elevated serum PSA. Sci Transl Med. 2011;3(94):94ra72.

144. Attard G, Swennenhuis JF, Olmos D, Reid AH, Vickers E, A'Hern R, et al. Characterization of ERG, AR and PTEN gene status in circulating tumor cells from patients with castration-resistant prostate cancer. Cancer Res. 2009; 69(7):2912-8. 
145. Brenner JC, Ateeq B, Li Y, Yocum AK, Cao Q, Asangani IA, et al. Mechanistic rationale for inhibition of poly(ADP-ribose) polymerase in ETS gene fusionpositive prostate cancer. Cancer Cell. 2011;19(5):664-78.

146. Chatterjee P, Choudhary GS, Alswillah T, Xiong X, Heston WD, Magi-Galluzzi $C$, et al. The TMPRSS2-ERG gene fusion blocks XRCC4-mediated nonhomologous end-joining repair and radiosensitizes prostate cancer cells to PARP inhibition. Mol Cancer Ther. 2015;14(8):1896-906.

147. Chatterjee P, Choudhary GS, Sharma A, Singh K, Heston WD, Ciezki J, et al. PARP inhibition sensitizes to low dose-rate radiation TMPRSS2-ERG fusion gene-expressing and PTEN-deficient prostate cancer cells. PLoS One. 2013;8(4), e60408.

148. Brazma A, Hingamp P, Quackenbush J, Sherlock G, Spellman P, Stoeckert C, et al. Minimum information about a microarray experiment (MIAME)-toward standards for microarray data. Nat Genet. 2001;29(4):365-71.

149. Kalyana-Sundaram S, Shanmugam A, Chinnaiyan AM. Gene Fusion Markup Language: a prototype for exchanging gene fusion data. BMC Bioinformatics. 2012;13:269.

150. Campbell PJ, Stephens PJ, Pleasance ED, O'Meara S, Li H, Santarius T, et al. Identification of somatically acquired rearrangements in cancer using genome-wide massively parallel paired-end sequencing. Nat Genet. 2008; 40(6):722-9.

151. Ottaviani $D$, LeCain $M$, Sheer $D$. The role of microhomology in genomic structural variation. Trends Genet. 2014;30(3):85-94

152. Nikiforova MN, Stringer JR, Blough R, Medvedovic M, Fagin JA, Nikiforov YE. Proximity of chromosomal loci that participate in radiation-induced rearrangements in human cells. Science. 2000;290(5489):138-41.

153. Mani RS, Tomlins SA, Callahan K, Ghosh A, Nyati MK, Varambally S, et al. Induced chromosomal proximity and gene fusions in prostate cancer. Science. 2009;326(5957):1230.

154. Lin C, Yang L, Tanasa B, Hutt K, Ju BG, Ohgi K, et al. Nuclear receptor-induced chromosomal proximity and DNA breaks underlie specific translocations in cancer. Cell. 2009;139(6):1069-83.

155. Stephens PJ, Greenman CD, Fu B, Yang F, Bignell GR, Mudie LJ, et al. Massive genomic rearrangement acquired in a single catastrophic event during cancer development. Cell. 2011;144(1):27-40.

156. Meyerson M, Pellman D. Cancer genomes evolve by pulverizing single chromosomes. Cell. 2011;144(1):9-10.

157. Moore PS, Chang Y. Why do viruses cause cancer? Highlights of the first century of human tumour virology. Nat Rev Cancer. 2010;10(12):878-89.

158. Peter M, Rosty C, Couturier J, Radvanyi F, Teshima H, Sastre-Garau X. MYC activation associated with the integration of HPV DNA at the MYC locus in genital tumors. Oncogene. 2006;25(44):5985-93.

159. Wentzensen N, Vinokurova S, von Knebel Doeberitz M. Systematic review of genomic integration sites of human papillomavirus genomes in epithelial dysplasia and invasive cancer of the female lower genital tract. Cancer Res. 2004;64(11):3878-84.

160. Sung WK, Zheng H, Li S, Chen R, Liu X, Li Y, et al. Genome-wide survey of recurrent HBV integration in hepatocellular carcinoma. Nat Genet. 2012;44(7):765-9.

161. Schmitz M, Driesch C, Jansen L, Runnebaum IB, Durst M. Non-random integration of the HPV genome in cervical cancer. PLoS One. 2012;7(6), e39632.

162. Feng $H$, Shuda M, Chang Y, Moore PS. Clonal integration of a polyomavirus in human Merkel cell carcinoma. Science. 2008;319(5866):1096-100.

163. Chung GT, Lung RW, Hui AB, Yip KY, Woo JK, Chow C, et al. Identification of a recurrent transforming UBR5-ZNF423 fusion gene in EBV-associated nasopharyngeal carcinoma. J Pathol. 2013;231(2):158-67. 